\title{
Recognition of Elicitors in Grapevine: From MAMP and DAMP Perception to Induced Resistance
}

\begin{abstract}
Marie-Claire Héloir ${ }^{1}$, Marielle Adrian ${ }^{1}$, Daphnée Brulé ${ }^{1}$, Justine Claverie ${ }^{1}$, Sylvain Cordelier2, Xavier Daire ${ }^{1}$, Stéphan Dorey2, Adrien Gauthier ${ }^{1,3}$, Christelle Lemaître-Guillier ${ }^{1}$, Jonathan Negrel ${ }^{1}$, Lucie Trdá ${ }^{1,4}$, Sophie Trouvelot ${ }^{1}$, Elodie Vandelle ${ }^{1,5}$ and Benoit Poinssot ${ }^{1 *}$
\end{abstract}

\begin{abstract}
${ }^{1}$ Agroécologie, Agrosup Dijon, CNRS, INRA, Univ. Bourgogne, Univ. Bourgogne Franche-Comté, Dijon, France, ${ }^{2}$ Unité RIBP EA 4707, SFR Condorcet FR CNRS 3417, University of Reims Champagne-Ardenne, Reims, France, ${ }^{3}$ UniLaSalle, AGHYLE Research Unit UP 2018.C101, Rouen, France, ${ }^{4}$ Laboratory of Pathological Plant Physiology, Institute of Experimental Botany, the Czech Academy of Sciences, Prague, Czechia, ${ }^{5}$ Laboratory of Plant Pathology, Department of Biotechnology, University of Verona, Verona, Italy
\end{abstract}

\section{OPEN ACCESS}

Edited by: Eva Maria Zyprian, Julius Kühn-Institut, Germany

Reviewed by:

Matthias Hahn,

University of Kaiserslautern, Germany

Daniela Pontiggia, Sapienza University of Rome,

Italy

*Correspondence: Benoit Poinssot benoit.poinssot@inra.fr

Specialty section: This article was submitted to Plant Microbe Interactions,

a section of the journal

Frontiers in Plant Science

Received: 19 April 2019 Accepted: 14 August 2019 Published: 18 September 2019

Citation:

Héloir M-C, Adrian M, Brulé $D$, Claverie J, Cordelier S, Daire X, Dorey S, Gauthier A, Lemaître-Guillier C,

Negrel J, Trdá L, Trouvelot S, Vandelle $E$ and Poinssot B (2019) Recognition of Elicitors in Grapevine: From MAMP and DAMP Perception to Induced Resistance.

Front. Plant Sci. 10:1117. doi: 10.3389/fp/s.2019.01117
In a context of a sustainable viticulture, the implementation of innovative eco-friendly strategies, such as elicitor-triggered immunity, requires a deep knowledge of the molecular mechanisms underlying grapevine defense activation, from pathogen perception to resistance induction. During plant-pathogen interaction, the first step of plant defense activation is ensured by the recognition of microbe-associated molecular patterns, which are elicitors directly derived from pathogenic or beneficial microbes. Vitis vinifera, like other plants, can perceive elicitors of different nature, including proteins, amphiphilic glycolipid, and lipopeptide molecules as well as polysaccharides, thanks to their cognate pattern recognition receptors, the discovery of which recently began in this plant species. Furthermore, damage-associated molecular patterns are another class of elicitors perceived by $V$. vinifera as an invader's hallmark. They are mainly polysaccharides derived from the plant cell wall and are generally released through the activity of cell wall-degrading enzymes secreted by microbes. Elicitor perception and subsequent activation of grapevine immunity end in some cases in efficient grapevine resistance against pathogens. Using complementary approaches, several molecular markers have been identified as hallmarks of this induced resistance stage. This review thus focuses on the recognition of elicitors by Vitis vinifera describing the molecular mechanisms triggered from the elicitor perception to the activation of immune responses. Finally, we discuss the fact that the link between elicitation and induced resistance is not so obvious and that the formulation of resistance inducers remains a key step before their application in vineyards.

Keywords: Vitis vinifera, innate immunity, defense responses, Pattern Recognition Receptor (PRR), MicrobeAssociated Molecular Pattern (MAMP), Damage-Associated Molecular Pattern (DAMP), Induced Resistance (IR)

\section{INTRODUCTION}

Vitis vinifera cultivars, cultivated worldwide for the production of table grape and wines, are susceptible to various pathogens, such as insects, viruses, bacteria, phytoplasmas, fungi, and oomycetes. The last two groups of microorganisms can rapidly and strongly impact the yield and the quality of the harvest. For example, the oomycete Plasmopara viticola and the ascomycete Erysiphe 
necator, the causal agents of downy and powdery mildews, respectively, infect leaves but also inflorescences and young green berries, while Botrytis cinerea, a necrotrophic fungus causing gray mold, affects berries during ripening. These devastating diseases are currently managed mainly through repeated treatments with synthetic fungicides for grape protection. However, the intensive use of chemicals has a negative impact on environment and human health and contributes to the selection of resistant pathogenic strains (Casida, 2009; Nanni et al., 2016). Thus, in the context of the integrated pest management, the implementation of a sustainable viticulture requires alternative/complementary strategies to chemical treatments. Among them, a recognized approach for crop protection is the stimulation of natural plant defense to trigger induced resistance (IR) (Walters et al., 2013; Delaunois et al., 2014).

Plants detect pathogen attack through the perception of conserved microbial signatures, called microbe-associated molecular patterns (MAMPs) or host-derived damage-associated molecular patterns (DAMPs), thanks to plant plasma membrane pattern recognition receptors (PRRs) (Boutrot and Zipfel, 2017). PRRs are generally receptor-like kinases (RLKs) or receptor-like proteins (RLPs) with an extracellular domain for MAMP/DAMP recognition (Trdá et al., 2015). MAMPs can be microbial structural components such as bacterial flagellin, lipopolysaccharides (LPSs), peptidoglycans (PGNs), rhamnolipids (RLs), fungal chitin, or oomycete $\beta$-glucans but also secreted toxins or enzymes like fungal xylanase or endopolygalacturonase (Figure 1). DAMPs are endogenous danger signals, such as oligogalacturonides (OGs) or cutin monomers, released from degraded plant cell wall or cuticle, respectively (Boller and Felix, 2009). The MAMP/DAMP perception triggers a complex cascade of signaling events, including ion fluxes such as $\mathrm{Ca}^{2+}$ influx, the production of reactive oxygen species (ROS) and nitric oxide, and the activation of mitogenactivated protein kinases (MAPKs). These early events induce a massive transcriptional reprogramming of primary and secondary metabolisms. The induction of specific defense-related genes leads to the synthesis of (i) pathogenesis-related (PR) proteins, including hydrolytic enzymes (e.g., $\beta$-1,3-glucanases or chitinases), which degrade pathogen cell wall; (ii) antimicrobial compounds like phytoalexins; (iii) compounds involved in cell wall reinforcement; and, in some cases, (iv) proteins involved in the hypersensitive response (HR), a form of programmed host cell death (GarciaBrugger et al., 2006). Altogether, these defense reactions represent the MAMP-triggered immunity (MTI), which is finely regulated by phytohormones (salicylic acid [SA], jasmonic acid [JA], and ethylene $[\mathrm{ET}]$ ) to finally prevent or delay pathogen infection, thus ensuring a basal plant resistance to pathogens.

The possibility of activating plant immunity using MAMPs or DAMPs led to the development of IR strategy to protect crops against pathogens. Indeed, the application of elicitors mimics a pathogen attack, stimulating basal plant defenses and thus leading to plant resistance, at least in controlled conditions (Wiesel et al., 2014). Elicitors can be purified MAMPs or DAMPs, molecules displaying similar structures or even extracts derivate from

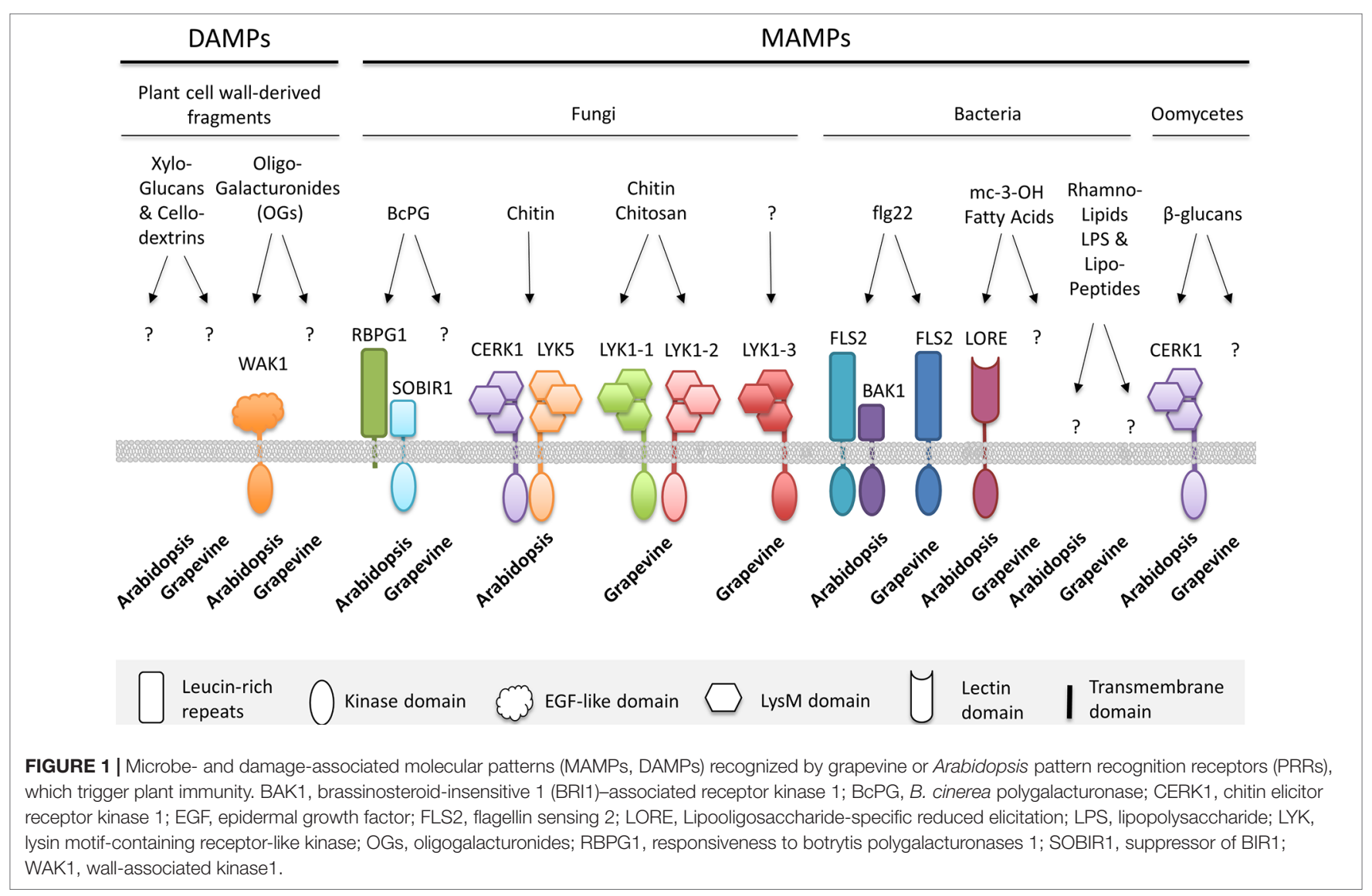


microorganisms or plants, and can have a biological or synthetic origin (Walters and Fountaine, 2009). For grapevine, several elicitors of various origins or structural patterns have been studied so far, and their mode of action has been well characterized (Delaunois et al., 2014). Some elicitors are able to induce a good level of resistance against pathogens in controlled conditions. For example, the $\beta$-glucan laminarin and its sulfated derivative (PS3) were shown to protect grapevine against $P$. viticola (Aziz et al., 2003; Trouvelot et al., 2008). Chitin and its deacetylated derivative chitosan act as MAMPs (Brulé et al., 2019) and induce grapevine resistance against $P$. viticola, E. necator, and B. cinerea (Trotel-Aziz et al., 2006; Aziz et al., 2007). Recently, it has been shown that a mixture of chitosan and OGs (COS-OGA) protects grapevine against powdery mildew in vineyards (van Aubel et al., 2014). Nevertheless, it is known that the efficacy of IR in the field is variable, depending on various biotic and abiotic factors (Adrian et al., 2012; Delaunois et al., 2014). Therefore, it is crucial to get a better understanding of IR mechanisms and to identify associated molecular markers.

In this review, we focus on the current knowledge about MAMPs/DAMPs which trigger immune responses in grapevine and also on their cognate PRRs in this plant. Moreover, we discuss the relation between the elicitation of immune responses and the actual IR, as well as the perspectives to improve the effectiveness of resistance inducers in a perspective of field application.

\section{ACTIVE MAMPs AND DAMPs PERCEIVED BY VITIS VINIFERA}

\section{The $B$. cinerea Endopolygalacturonase 1 (BcPG1) and its Activity-Derived Products (OGs) Are Distinct Interconnected Elicitors That Activate Independently Grapevine Immune Responses}

Bacterial or fungal necrotrophic phytopathogens secrete numerous plant cell wall-degrading enzymes (CWDEs) to break down the cell wall polymers, such as cellulose, hemi-cellulose, and pectin, and invade host tissues. The degradation of host cell wall then contributes to the development of soft rots or molds. Among necrotrophs, $B$. cinerea, an opportunistic plant pathogenic fungus able to cause rot in many plant tissues, including in grapevine, produces a variety of pectinases, including exo- and endopolygalacturonases, pectin methylesterases, pectin, and pectate lyases (ten Have et al., 2002; Zhang and van Kan, 2013). In particular, its genome encodes for six endopolygalacturonases (BcPG1-6), the expression of which varies depending on plant tissues (ten Have et al., 1998; ten Have et al., 2001). The biochemical characterization of their enzymatic activity and the production of deletion mutants of $B c P G 1$ and $B c P G 2$ demonstrated their capacity to produce tissue collapse and necrosis as well as their role in $B$. cinerea virulence on tomato, apple, broad bean, and Arabidopsis thaliana (hereafter Arabidopsis) (ten Have et al., 1998; Kars et al., 2005). The availability of a set of endoPGs with slightly different characteristics in terms of substrate specificity might enable the pathogen to hydrolyze a larger spectrum of pectin types, originating from different host species.
The degradation of pectin by polygalacturonases leads to the release of intermediate products, called OGs, which have been shown to act in vivo as DAMPs, protecting plants from infection by necrotrophic pathogens (Benedetti et al., 2015). OGs are a-1,4-linked galacturonosyl residues with different degrees of polymerization (DP) and esterification, which may influence their elicitor activity. Indeed, based on several transcriptomic studies, long OGs (DP > 10) have long been thought to be the only efficient pectin fragments for triggering plant defense responses (Moscatiello et al., 2006; Ferrari et al., 2007; Denoux et al., 2008). However, although short OGs suppress defense responses in wheat (Moerschbacher et al., 1999), they can also induce a strong defense gene expression in other plants, such as Arabidopsis, potato, and tomato (Simpson et al., 1998; Norman et al., 1999). Recently, a comparison of gene expression reprogramming, induced by both long (DP > 10) and short (DP3) OGs, revealed actually a great similarity of the response, in qualitative and quantitative terms, confirming that both long and short OGs are potentially biologically active, at least in Arabidopsis (Davidsson et al., 2017).

The formation of OGs during plant-pathogen interactions is promoted by polygalacturonase-inhibiting proteins (PGIPs) (Kalunke et al., 2015). These plant cell wall proteins selectively and partially inhibit PGs produced by pathogenic microorganisms allowing the accumulation of OGs, as intermediate reaction products, which are active elicitors of plant defense responses. In particular, expression of the grapevine VvPGIP1 in tobacco was shown to improve plant resistance against $B$. cinerea, through the partial inhibition of some fungal PGs, including BcPG1 (Joubert et al., 2006). On the other hand, OGs can be inactivated by berberine bridge enzyme (BBE)like proteins, which act as specific OG oxidases (Benedetti et al., 2018). Through such in vivo OG oxidase (OGOX) activity, oxidized OGs become less active as defense inducers and less susceptible to hydrolysis by fungal PGs. It has been proposed that this mechanism may prevent the deleterious excessive OG accumulation, which may compromise plant growth and resistance through cell death induction, when reaching high concentrations (Cervone et al., 1987). Although OGOX activity has still to be identified in grapevine, it is reasonable to assume that OG turnover may be controlled in the same way to ensure grapevine growth-immunity trade-off.

Some strains of $B$. cinerea are unable to develop on grapevine, likely due to the induction of strong plant defense responses and the incapacity of the fungus to counteract such defense mechanisms (Derckel et al., 1999). Accordingly, an eliciting activity was found in the filtrate of the T4 strain of $B$. cinerea, nonpathogenic on grapevine, and, surprisingly, attributed to the protein BcPG1 (Poinssot et al., 2003). The protein BcPG1 was also more abundant in the nonpathogenic A336 mutant of B. cinerea, impaired in plant colonization capacity, and compared to the wild-type pathogenic strain Bd90, and this larger BcPG1 amount was correlated with the induction of a strong oxidative burst in grapevine cells (Kunz et al., 2006). It was thus assumed that the overproduction of BcPG1 may boost plant defense reactions against the mutant strain, thus contributing to its reduced pathogenicity. Interestingly, BcPG1 elicitor activity was not related to its enzymatic activity, i.e., from release of OGs from grapevine cell wall, but rather relied on the recognition of the protein itself (Poinssot et al., 2003). In particular, 
besides the overall lower intensity of defense responses induced by OGs compared to BcPG1, grapevine cells pre-treated with OGs were not desensitized to the successive application of BcPG1, and vice versa, indicating the existence of two different receptors/ pathways leading to defense induction (Figure 2A). Moreover, BcPG1 elicitor and enzymatic activities were discriminated by inhibiting selectively one or the other through different protein treatments (Poinssot et al., 2003). This study thus demonstrated that BcPG1 functions as a MAMP and that particular protein patterns may be responsible for defense induction, as previously reported for other CWDEs, such as the $22-\mathrm{kDa}$ fungal protein ethylene-inducing xylanase (EIX), which per se functions as an elicitor, independently of its enzymatic activity (Enkerli et al., 1999; Furman-Matarasso et al., 1999; Rotblat et al., 2002). The challenging aspect in the elucidation of plant defense mechanism induction is the identification of perception systems, which have been often characterized using the model plant Arabidopsis, allowing genetic studies. Wall-associated kinases (WAKs) have been proposed for a long time as candidates for the perception of OGs (Figure 1). These proteins possess a typical intracellular Ser/Thr kinase domain and an apoplastic domain containing several epidermal growth factor (EGF)-like repeats interacting with the cell wall. The role of WAK RLKs in plant immunity has been demonstrated in several plant species, including Arabidopsis, rice, maize, and more recently tomato and wheat (Diener and Ausubel, 2005; Zhang et al., 2005; Li et al., 2009; Rosli et al., 2013; Hurni et al., 2015; Zuo et al., 2015; Delteil et al., 2016; Harkenrider et al., 2016; Zhang et al., 2017; Saintenac et al., 2018; Yang et al., 2019). In Arabidopsis, WAKs are encoded by five tightly linked and highly similar genes and several reports demonstrated in particular the capacity of WAK1 to bind OGs in vitro through the $\mathrm{N}$-terminal ectodomain (Wagner and Kohorn, 2001; Decreux et al., 2006; Cabrera et al., 2008). Moreover, WAK1 was the only member of the gene family to be up-regulated in response to OGs treatment (Denoux et al., 2008). To overcome the limits of reverse genetics due to redundancy and lethality of WAK silencing (Wagner and Kohorn, 2001), an elegant domain swap approach, using the construction of a chimeric receptor, demonstrated the function of WAK1 as a receptor of OGs and its role in defense response induction in Arabidopsis (Brutus et al., 2010). WAK1-mediated OG-induced responses were shown to be then negatively regulated by two WAK1 interactors, namely, the glycin-rich protein GRP-3 and a kinase-associated protein phosphatase (KAPP), which likely contribute to phase out the plant immune response (Gramegna et al., 2016).

On the other hand, by exploiting the capacity of $B$. cinerea PGs to induce different levels of necrosis formation in different Arabidopsis accessions, a map-based cloning strategy combined with comparative and functional genomics allowed the identification of the RLP RBPG1 (RESPONSIVENESS TO BOTRYTIS POLYGALACTURONASES 1) as endoPG receptor in Arabidopsis (Zhang et al., 2014). Lacking a cytoplasmic functional domain, the RBPG1 function as PRR relies on its interaction with the RLK SOBIR1 (for SUPPRESSOR OF BIR1). The formation of the RBPG1/SOBIR1 heterodimer, unaffected by the BcPG3 ligand, likely ensures intracellular signal transduction through SOBIR1 kinase activity (Figure 1). RBPG1 not only interacts with $\mathrm{BcPG} 3$ but also recognizes multiple active and inactive PGs from B. cinerea. Since the response of Arabidopsis to PGs appears different from that reported in other plant species (Kars et al., 2005; Joubert et al., 2007; Zhang et al., 2014), the identification of homologs of AtRBPG1, or other RLPs, should be carried out in $V$. vinifera to characterize its perception system for BcPG1.

Following OGs and BcPG1 perception, several studies reported a detailed description of the induced signaling events using pharmacological, biochemical, and genetic approaches. Both elicitors trigger an increase of cytosolic $\mathrm{Ca}^{2+}$ concentration

\section{A}

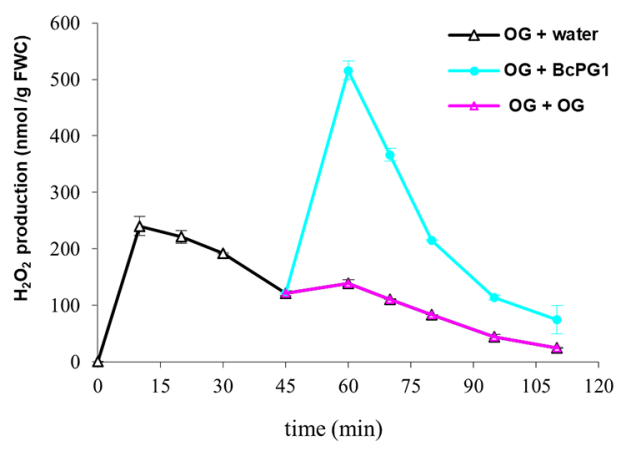

B

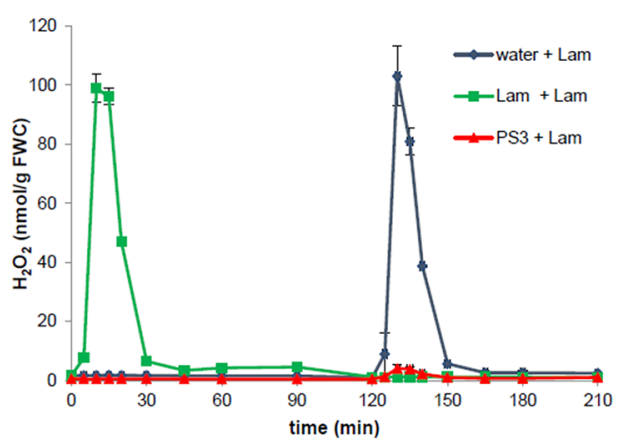

FIGURE 2 | Desensitization experiments can differentiate MAMPs/DAMPs perceived by independent or common receptors in grapevine. (A) Desensitization experiments reveals that BcPG1 and OGs are perceived differently by grapevine cells as the $\mathrm{H}_{2} \mathrm{O}_{2}$ production is abolished after two successive treatments with OG (pink) but not when BcPG1 (cyan) succeeds to a first treatment with OGs (black). Cells were first treated at time 0 with $0 \mathrm{Gs}(200 \mathrm{\mu g} / \mathrm{ml}$; black), washed three times between 30 and 45 min with fresh medium, then treated a second time with OGs ( $200 \mu \mathrm{g} / \mathrm{ml}$; pink), BcPG1 (0.2 $\mu \mathrm{g} / \mathrm{ml}$; cyan), or water (black). $\mathrm{H}_{2} \mathrm{O}_{2}$ production was determined using chemiluminescence of luminol as described by Poinssot et al. (2003). (B) Refractory state experiments revealed that the two $\beta$-glucan derivatives (PS3 and Lam) might be perceived by the same receptor in grapevine cells as a first treatment with PS3 abolishes the oxidative burst normally elicited by laminarin. Cells were first treated at time 0 with water (black), laminarin (Lam, 4 mg/ml; green), or PS3 (4 mg/ml; red); washed three times between 90 and 120 min with fresh medium; and then treated a second time with laminarin $(4 \mathrm{mg} / \mathrm{ml}) . \mathrm{H}_{2} \mathrm{O}_{2}$ production was determined using chemiluminescence of luminol as described by Gauthier et al. (2014). Data are means \pm SE of duplicates, representative of three independent experiments. FWC, fresh weight of cells. 
$\left(\left[\mathrm{Ca}^{2+}\right]_{\text {cyt }}\right)$ (Lecourieux et al., 2002; Vandelle et al., 2006). $\mathrm{Ca}^{2+}$ increase controls in turn the oxidative burst, which involves the activity of NADPH oxidases (Vandelle et al., 2006; Galletti et al., 2008) but also the production of nitric oxide (NO) (Vandelle et al., 2006; Rasul et al., 2012) by a NO synthase activity that still needs to be further characterized (Jeandroz et al., 2016). Independently of the above-mentioned physiological events, both BcPG1 and OGs activate two MAPKs related to AtMPK3 and AtMPK6 (Vandelle et al., 2006; Denoux et al., 2008; Galletti et al., 2011). Finally, as later events, both elicitors induce a set of defense-related genes and the production of phytoalexins, contributing to plant resistance.

The secretion of CWDEs by $B$. cinerea occurs constitutively. In particular, Bcpg1 (together with Bcpg2) is among the earliest expressed fungal genes during the infection of tomato leaves, suggesting that the corresponding enzyme may play a role in early stages of the infection process (ten Have et al., 2001). Since the activation of PRR-mediated immunity aims at inhibiting pathogen development at early stages of infection (Melotto et al., 2006; Zeng and He, 2010), the early BcPG1 expression fits well with a possible rapid perception of the pathogen by grapevine cells. Moreover, its crucial role in pathogenicity makes it an indispensable element for the pathogenic fungus, and this supports further plant adaptation to recognize this protein that may remain stable in fungus genome to maintain its virulence, concept at the basis of the gene-for-gene/guard and decoy models (van der Hoorn and Kamoun, 2008). We could thus assume a scenario in which BcPG1 may represent the main elicitor of defense reactions. However, in case of perception failure by host cells, for instance in absence of the proper receptor, the enzymatic activity of BcPG1, regulated by PGIPs, would lead to the production of active OGs able to trigger grapevine immunity. Although less intense, this alternative defense layer may ensure the induction of a general mechanism of resistance to fight against $B$. cinerea infection and would be secured by the further inactivation of OGs by OGOXs once reached a concentration threshold.

\section{The Cell Wall-Derived Xyloglucans and Cellodextrins Are New DAMPs That Elicit Immune Responses in Grapevine}

It has been previously reported that xyloglucan oligosaccharides, the main component of hemicellulose, play a role in cell wall structure (Takeda et al., 2002; Whitney et al., 2006), in the development and the regulation of plant growth in different plant species (Fry et al., 1993; Vargas-Rechia et al., 1998) and can also act as a storage polysaccharide to provide energy for the emerging seedlings (dos Santos et al., 2004). Interestingly, xyloglucans were recently discovered as new DAMPs in grapevine and Arabidopsis (Claverie et al., 2018).

In grapevine, xyloglucans elicit a broad range of defense responses, including the activation of two MAPKs and the production of the phytoalexin resveratrol, correlated with the induction of the expression of defense genes, involved in particular in the phenylpropanoid pathway and resveratrol biosynthesis. Importantly, xyloglucans are able to protect grapevine detached leaves against $B$. cinerea (Claverie et al., 2018). Besides grapevine, xyloglucans also trigger the phosphorylation of MAPKs, defense gene expression, and callose deposition, through the callose synthase PMR4 in Arabidopsis (Luna et al., 2011), and confer resistance against $B$. cinerea and the biotrophic oomycete Hyaloperonospora arabidopsidis. The use of Arabidopsis mutants allowed to provide evidence that xyloglucan-mediated resistance against $B$. cinerea involves different defense pathways, including camalexin, SA, JA, and ethylene (Claverie et al., 2018). Compared to OGs, the immune responses induced by xyloglucans are strikingly different in terms of kinetics and strength of the response or activated immune responses. Indeed, xyloglucans do not elicit $\mathrm{H} 2 \mathrm{O} 2$ production neither in grapevine nor in Arabidopsis cells, while OGs trigger resistance against $B$. cinerea independently of SA, JA, and ethylene (Ferrari et al., 2007). These results suggest that different DAMPs could operate through different signaling pathways.

Xyloglucan oligomers are characterized by a $\beta-1,4$ glucan backbone resembling that of cellodextrins (CDs). CDs and cellobiose are cellulose-derived oligomers from the cell wall that also act as DAMPs, eliciting $\left[\mathrm{Ca}^{2}+\right]_{\text {cyt }}$ variations, defense gene activation, and protection against pathogens in Vitis vinifera and Arabidopsis (Aziz et al., 2007; Souza et al., 2017). As shown for OGs, the elicitor activity of CDs can be impaired by a member of the BBE-like protein family in Arabidopsis, namely, the cellodextrin oxidase (CELLOX), via the oxidation of their reducing end, likely as a general mechanism of BBE-like proteins to avoid oligosaccharide hyperaccumulation (Locci et al., 2019). Moreover, a poly(A)ribonuclease controls the cellotriosebased interaction between Arabidopsis and the plant-growthpromoting endophyte Piriformospora indica suggesting a major role of this enzyme in regulating the outcome of this beneficial interaction (Johnson et al., 2018).

The structure of the oligosaccharide elicitors also plays an important role in their biological activity. For example, xyloglucans used in our study were mainly constituted of a $\beta$-1,4-glucan backbone associated with xylosyl-, galactosyl-, and fucosyl-type branching, with a DP of 7 (Claverie et al., 2018). The order and the type of substituents depend on the plant species, the cell type, and the developmental state of the cell (Pauly and Keegstra, 2016). As indicated above for OGs, the biological activity of oligosaccharides is known to be dependent on their DP and decoration pattern. Accordingly, only CDs with a DP $>7$ are able to induce a strong production of $\mathrm{H} 2 \mathrm{O} 2$, the overexpression of defense genes associated with an increase in chitinase and glucanase activities, finally leading to an IR against $B$. cinerea (Aziz et al., 2007). The future comparison of immune responses triggered by xyloglucans possessing different carbohydrate decorations would therefore deserve further investigations and might lead to interesting applications for crop protection.

Overall, the activation of immune responses in grapevine and Arabidopsis strengthens the notion that these two plant species can perceive hemicellulose and cellulose-derived oligomers and that at least one cognate receptor exists. As Arabidopsis perceive xyloglucans and cellobiose, it should be envisaged to first isolate their PRR(s) through a genetic approach, and then identify their orthologs in V. vinifera. 


\section{The Grapevine LysM Receptors VvLYK1-1 and VvLYK1-2 Recognize Chitin and Chitosan Fragments to Elicit Similar Immune Responses}

Chitooligosaccharides (COS), especially chitin and chitosan, are representative MAMPs known to induce immune responses in a wide range of plant species such as Arabidopsis (Miya et al., 2007; Cao et al., 2014) or rice (Hayafune et al., 2014). Chitin, a linear homopolymer of $\beta-1,4 \mathrm{~N}$-acetylglucosamine (GlcNAc), is a major structural component of fungal cell walls, Crustacean shells, and the exoskeleton of insects and nematodes. Chitosan, the deacetylated chitin derivative produced by chitin deacetylases, is also a naturally occurring polysaccharide, albeit less common. Chitosan can be notably found in some fungal species such as Cryptococcus neoformans (Baker et al., 2007). Since the 1980s, chitin and its deacetylated product chitosan have been used for crop farming as biopesticides, biofertilizers, for seed coating formulation, and agricultural film (El Hadrami et al., 2010; Hadwiger, 2013; Trouvelot et al., 2014). Both molecules are known to induce the biosynthesis of several antimicrobial compounds, namely, phytoalexins (Vasiukova et al., 2001), callose (Ren et al., 2001), and lignin (Barber et al., 1989). Many studies have reported that COS enhance plant defenses against bacteria (Rabea et al., 2003; Tikhonov et al., 2006), fungi (Park et al., 2002; Trotel-Aziz et al., 2006) and nematodes (Khalil and Badawy, 2012; Nunes da Silva et al., 2014).

Chitin hexa-, hepta-, or octamers are recognized by the lysin motif (LysM)-RLK chitin elicitor receptor kinase 1 (CERK1/LYK1) and LysM-containing receptor-like kinase5 (LYK5) in Arabidopsis (Miya et al., 2007; Wan et al., 2008; Petutschnig et al., 2010; Cao et al., 2014), by the complex OsCERK1/chitin elicitor-binding protein (OsCEBiP) in rice (Kaku et al., 2006; Shimizu et al., 2010) or by their ortholog complex MtLYK9/MtLYR4 in legumes such as Medicago truncatula (Bozsoki et al., 2017). Plant LysM domain proteins are required for chitin-binding and signaling and serve as modules mediating plant immunity and stopping pathogen infection. For instance, in line with AtCERK1 function in chitin recognition in Arabidopsis, the corresponding knockout mutant Atcerk1/ $l y k 1$, which completely lost its ability to respond to the elicitor, is more susceptible to the fungal pathogen Alternaria brassicicola and to the bacterial pathogen Pseudomonas syringae (Miya et al., 2007; Gimenez-Ibanez et al., 2009). In grapevine, a phylogenetic analysis highlighted three LysM proteins VvLYK1-1, VvLYK12, and VvLYK1-3, among 15, which are putative orthologues of the Arabidopsis AtCERK1/LYK1 and the rice OsCERK1 (Brulé et al., 2019). The functional complementation of the Arabidopsis Atcerk1 mutant with the three grapevine orthologs of AtCERK1/ LYK1 demonstrated that the constitutive expression of $V v L Y K 1-1$ or the inducible expression of VvLYK1-2, but not VvLYK1-3, restored COS-induced immune responses (Brulé et al., 2019). These results suggested that the same PRRs, VvLYK1-1, and VvLYK1-2 are involved in COS-triggered immunity in grapevine (Figure 1). Moreover, VvLYK1-1 expression in the Atcerk1 mutant background was demonstrated to restore non-host resistance against the grapevine powdery mildew $E$. necator.

Downstream $V$. vinifera receptor activation, chitosan elicits phytoalexins, chitinase, and glucanase activities leading to resistance against $B$. cinerea and $P$. viticola (Aziz et al., 2006; Trotel-Aziz et al., 2006). More precisely, hexamers of chitin and chitosan elicit the phosphorylation of MAPKs, phytoalexin production, and expression of defense genes, finally inducing resistance against the necrotrophic fungus $B$. cinerea and the obligate biotrophic oomycete P. viticola (Brulé et al., 2019). However, chitin hexamer do not induce any oxidative burst, contrary to what is observed in Arabidopsis (Miya et al., 2007).

\section{The Flagellin-Derived Peptides Flg22 From Pathogenic or Beneficial Bacteria Recognized by the Grapevine VvFLS2 Receptor Do Not Elicit Similar Immune Responses}

Flagellin, the main building protein of eubacterial flagella, is a potent defense elicitor in different plant species and is one of the best studied MAMPs. Plants perceive flagellin mainly through the $\mathrm{N}$-terminal conserved epitope of 22 amino acids, called flg22. Flg22 peptide from Pseudomonas aeruginosa is a commonly used MAMP to study the responses to flagellin in a broad variety of plant species (Boller and Felix, 2009). Using V. vinifera cell suspensions, flg22 was shown to be also an active MAMP in grapevine (Trdá et al., 2014).

The plant PRR responsible for flagellin/flg22 perception is the leucine-rich repeat receptor like kinase (LRR-RLK) flagellin sensing 2 (FLS2) (Gomez-Gomez and Boller, 2000; Chinchilla et al., 2006). FLS2 was first identified in Arabidopsis (AtFLS2) (Gomez-Gomez and Boller, 2000), and functional FLS2 orthologues were further shown to be conserved within the plant kingdom (Boller and Felix, 2009). Among them, a clear orthologue of AtFLS2 was identified in the grapevine genome, namely, VvFLS2, encoding a protein displaying a conserved domain structure. The functionality of VvFLS2 as a grapevine flagellin receptor (Figure 1) was demonstrated through the successful complementation of the corresponding Arabidopsis mutant fls2, which successfully restored flg22-induced $\mathrm{H} 2 \mathrm{O} 2$ production (Trdá et al., 2014), as previously shown for the rice OsFLS2 or the tomato LeFLS2 (Takai et al., 2008; Mueller et al., 2012). At molecular level, the perception of flg22 in grapevine by VvFLS2 triggers common rapid and transient signaling responses, such as an increase in free $\left[\mathrm{Ca}^{2+}\right]_{\mathrm{cyt}}$, the phosphorylation of two MAPKs with relative molecular masses of 45 and $49 \mathrm{kDa}$ and an oxidative burst. Later, flg22 perception activates the expression of a set of defense genes (e.g., genes encoding the acidic chitinase Chit4c and the protease inhibitor PR6). Finally, flg22-elicited responses leads to a partial resistance of grapevine against $B$. cinerea (Trdá et al., 2014).

Previous studies have reported different recognition specificities between FLS2 from tomato and Arabidopsis (Felix et al., 1999; Bauer et al., 2001; Sun et al., 2006; Robatzek et al., 2007; Mueller et al., 2012). Interestingly, expressing VvFLS2 in the fls 2 background of Arabidopsis conferred a flagellin responsiveness profile specific to grapevine. Indeed, while different flg22 peptides, derived from different bacteria, exhibited comparable biological activities in Arabidopsis, they showed distinct eliciting activities in grapevine, and such species-specific differences in flg22 perception 
were caused, at least in part, by the nature of Arabidopsis and grapevine FLS2 proteins. Burkholderia phytofirmans is a plant growth-promoting rhizobacterium (PGPR) naturally associated with grapevine (Ait Barka et al., 2000; Compant et al., 2005; Lo Piccolo et al., 2010) which modifies grapevine metabolism thus promoting an improved plant growth, a better tolerance to B. cinerea infection as well as to cold stress (Ait Barka et al., 2000; Ait Barka et al., 2006; Fernandez et al., 2012; Theocharis et al., 2012). Furthermore, it can also trigger grapevine defense responses, including extracellular medium alkalization and defense gene expression, suggesting that it is potentially perceived via MAMP detection (Bordiec et al., 2011). Accordingly, the flagellin purified from $B$. phytofirmans induces $P R 1$ gene expression in Arabidopsis. Similarly, flg22 from this endophytic bacterium (Bp flg22) triggers immune responses also in grapevine, but weaker than the responses triggered by flg22 peptides derived from the pathogenic bacteria Xanthomonas campestris (Xc flg22) (Table 1) or $P$. aeruginosa ( $P a$ flg22) (Trdá et al., 2014). In addition, Bp flg22triggered gene expression is very low and transient compared with the long-lasting effect of $X c$ flg22 and $P a$ flg22 treatment, and some genes-for instance, PR6 or the grapevine SA marker gene 17.3 (Bordiec et al., 2011), are not significantly activated by $B p$ flg 22 treatment. Finally, unlike $X c$ flg22, Bp flg22 does not significantly inhibit grapevine plantlet growth (Trdá et al., 2014). While B. phytofirmans is naturally colonizing grapevine, it can colonize Arabidopsis only under laboratory conditions (Poupin et al., 2013; Zuniga et al., 2013), and it was therefore proposed that alterations in the $B p$ flg22 sequence might represent a successful adaptation of $B$. phytofirmans to avoid recognition by the host VvFLS2 and activation of immune system.

Key amino acids described as crucial for flg22-eliciting activity (Felix et al., 1999; Bauer et al., 2001; Sun et al., 2006) are unchanged in $B p$ flg22. Nevertheless, three amino acid substitutions between the most active peptide in grapevine $X c$ flg22 and Bp flg22 are sufficient to explain this different sensitivity. The pathogenic bacterium responsible for crown gall disease, Agrobacterium tumefaciens, also possesses 12 mutations in flg22 avoiding the FLS2 recognition and the subsequent immune responses (Table 1). On the other hand, the fact that AtFLS2 and VvFLS2 do not similarly perceive different flg22 epitopes, especially Bp flg22, suggests that VvFLS2 has evolved to distinguish flagellin originating from the grapevine-associated PGPR B. phytofirmans. Therefore, VvFLS2 and/or flagellin from $B$. phytofirmans may have undergone evolutionary changes allowing the adapted endophytic bacterium to colonize its natural host plants without inducing a strong MTI. Of interest, not only
B. phytofirmans evades perception by grapevine receptor, but it also seems to overcome flg22-induced MTI to efficiently colonize grapevine plants. Indeed, the application of the strong elicitor $X c$ flg22 to the roots of grapevine plantlets during the first stage of bacterization did not affect the process of plant colonization by B. phytofirmans. VvFLS2 thus represents the first example of a characterized receptor that differentially recognizes flg22 epitopes from a PGPR and plant-pathogenic bacteria, suggesting an evolutionary mechanism of grapevine innate immunity evasion by its beneficial endophytic bacterium B. phytofirmans.

\section{Rhamnolipids, LPS, and Cyclic Lipopeptides Are Recognized by Grapevine and Trigger-Induced Resistance}

Amphiphilic glycolipid and lipopeptide compounds have been recently identified as effective inducers of immune response in grapevine. Among them, bacterial RLs are the best characterized. Within the first hour after treatment, RLs from $P$. aeruginosa and Burkholderia plantarii trigger strong early signaling events in grapevine cell suspensions as well as defense markers, including genes encoding PR proteins or enzymes involved in oxylipin and phytoalexin biosynthesis pathways, and a programmed cell death reminiscent of animal apoptosis at high concentrations (Varnier et al., 2009). Furthermore, RLs potentiate defense responses induced by other elicitors and induce a local resistance of grapevine against the necrotrophic fungus B. cinerea (Varnier et al., 2009; Vatsa et al., 2010) but also an effective protection of Brassica napus and Arabidopsis toward fungal diseases (Sanchez et al., 2012; Monnier et al., 2018). In Arabidopsis, RL-mediated resistance involves different signaling pathways that depend on the type of pathogen. While JA is essential for the resistance to $B$. cinerea, the ET-mediated signaling pathway is involved in Arabidopsis resistance to the oomycete $H$. arabidopsidis and the bacterium Pseudomonas syringae pv. tomato (Sanchez et al., 2012). SA-dependent plant defenses are primed by RLs following pathogen infections suggesting that SA also participates to the restriction of these pathogens. How RLs are perceived by plant cells is still unclear. A recent report suggested that RLs could insert within the lipid bilayer of plant membranes leading to a moderate membrane destabilization influenced by the nature of the phytosterols. The resulting changes in lipid dynamics could have a direct impact on plant defense induction (Monnier et al., 2019). In grapevine, RLs trigger a very strong $\mathrm{Ca}^{2+}$ influx (Varnier et al., 2009), with concentrations of free cytosolic calcium reaching values higher than the concentrations detected

TABLE 1 | Intensity of the immune responses, in Vitis vinifera and Arabidopsis thaliana, following treatment with $1 \mu \mathrm{M}$ of flagellin-derived flg22 epitopes derived from beneficial or pathogenic bacteria. ++, highly induced; +, induced; +/-, weakly induced; -, not induced; PGPR, plant growth-promoting bacteria. Results from Trdá et al., 2014.

\begin{tabular}{|c|c|c|c|c|c|c|c|c|}
\hline \multirow[t]{2}{*}{ Bacteria } & \multirow[t]{2}{*}{ Type } & \multirow{2}{*}{$\begin{array}{l}\text { Flagellin } \\
\text { epitope }\end{array}$} & \multicolumn{3}{|c|}{ Vitis vinifera } & \multicolumn{3}{|c|}{ Arabidopsis thaliana } \\
\hline & & & $\begin{array}{c}\qquad \mathrm{H}_{2} \mathrm{O}_{2} \\
\text { production }\end{array}$ & $\begin{array}{c}\text { Defense gene } \\
\text { expression }\end{array}$ & $\begin{array}{c}\text { Plant growth } \\
\text { inhibition }\end{array}$ & $\begin{array}{c}\mathrm{H}_{2} \mathrm{O}_{2} \\
\text { production }\end{array}$ & $\begin{array}{c}\text { Defense gene } \\
\text { expression }\end{array}$ & $\begin{array}{c}\text { Plant growth } \\
\text { inhibition }\end{array}$ \\
\hline B. phytofirmans & PGPR & Bp flg22 & $+/-$ & $+/-$ & $+/-$ & ++ & ++ & ++ \\
\hline$X$. campestris & Pathogen & Xc flg22 & ++ & ++ & ++ & ++ & ++ & ++ \\
\hline A. tumefaciens & Pathogen & At flg22 & - & - & - & - & - & - \\
\hline
\end{tabular}


after the treatment of tobacco cell suspensions with the potent elicitor cryptogein (Lamotte et al., 2004). This $\mathrm{Ca}^{2+}$ signature seems to be very characteristic when compared with the signatures described for other elicitors (Garcia-Brugger et al., 2006) and could be related to the potential destabilization of grapevine cell membranes. Synthetic RL structures that induce a plant immune response are also able to interact with lipids from plant membrane models, suggesting that the perception of these molecules could involve a lipid-driven process (Nasir et al., 2017; Luzuriaga-Loaiza et al., 2018).

LPSs are complex amphiphilic glycolipids composed of a lipidic part (lipid-A), a conserved oligosaccharidic core, and an O-polysaccharidic part with variable length and composition (OPS) (Caroff and Karibian, 2003). They are present in the outer bilayer of the plasma membrane of most Gram-negative bacteria. While the lipid-A and the oligosaccharidic core are relatively well conserved, the OPS is chemically and structurally very heterogeneous among species. OPS is composed of polymers of several monosaccharide repeat units, and its variability depends on bacterial species (Lerouge and Vanderleyden, 2002). While the lipid-A is embedded in the outer membrane, the OPS is oriented outward of the membrane, thus being directly at the interface between the bacterium and the host during the interaction. The OPS plays an essential role in stress resistance, protecting bacteria against hostile environment and is considered as an important virulence factor for pathogenic bacteria during the colonization of their host (Clifford et al., 2013; Di Lorenzo et al., 2016). Phytopathogenic bacteria lacking OPS are generally considered less viable inside the host plant and are therefore expected to be nonvirulent. For example, OPS mutants of Erwinia amylovora, Ralstonia solanacearum, Xanthomonas axonopodis pv. citri, or Xylella fastidiosa are significantly less virulent than their respective wild-type strains (Berry et al., 2009; Petrocelli et al., 2012; Clifford et al., 2013; Li et al., 2014). In contrast, host plants have developed perception systems of these LPSs leading to the induction of defense mechanisms to counter the invasion of pathogenic bacteria (Ranf et al., 2016). LPSs are considered as MAMPs and induce defensive responses, including ROS production, in several plant species such as Arabidopsis, tobacco, rice, or grapevine (Braun et al., 2005; Silipo et al., 2005; Desaki et al., 2006; Rapicavoli et al., 2018). In grapevine, Agrobacterium vitis and Xylella fastidiosa, two Gram-negative pathogenic bacteria, cause crown gall and Pierce's disease, respectively. A. vitis LPS extracts infiltrated into grapevine internodes protect the plant from tumor appearance following $A$. vitis infection (Alexandrova et al., 2000). Similarly, LPSs purified from X. fastidiosa induce a rapid production of ROS in grapevine leaf disks. Interestingly, OPS-deficient $X$. fastidiosa bacteria cause a higher production of ROS in vitro and in vivo compared to wild-type bacteria (Rapicavoli et al., 2018). Grapevine plants pre-treated with LPSs from the OPS-deficient $X$. fastidiosa strain showed a strongly attenuated development of the symptoms caused by $X$. fastidiosa in comparison with grapevine plants pretreated with purified LPSs from wild-type $X$. fastidiosa strain (Rapicavoli et al., 2018). The presence of the OPS therefore delays the immune perception of $X$. fastidiosa by grapevine cells, probably by masking the MAMP motifs on the cell surface. The OPS is also likely involved in bacterial virulence, especially in biofilm formation and motility, and therefore related to its ability to enter and spread within the host (Kutschera and Ranf, 2019). In Arabidopsis, it was recently shown that the lectin receptor S-domain receptor kinase AtLORE (LIPOOLIGOSACCHARIDE-SPECIFIC REDUCED ELICITATION, Figure 1) recognizes the medium chain 3-hydroxy fatty acid brick present in the lipid A part of LPSs but does not sense lipid A or LPSs themselves (Kutschera et al., 2019). Phylogenetically, this receptor seems to be specific of the Brassicaceae family (Ranf et al., 2015). Lipid-A from Pseudomonas seems also perceived by Arabidopsis as it induces a late oxidative burst, presumably not driven by the LORE receptor (Shang-Guan et al., 2018). This LOREindependent perception suggests that LPSs may be perceived by distinct perception mechanisms leading to the induction of the plant immune system. In rice, the perception of LPSs rather involves the OsCERK1 receptor, which also senses the lipid-A (Desaki et al., 2018). Bioinformatics and genetic approaches looking for homologous LORE-like or CERK1like receptors might allow the identification of receptors involved in LPS perception by grapevine cells.

Lipopeptides produced by bacteria are also amphiphilic compounds perceived by plants as MAMPs (Ongena and Jacques, 2008). Bacillus subtilis produces three main families of cyclic lipopeptides (LPs), namely, surfactins, iturins, and fengycins. Purified surfactin, mycosubtilin (iturin family), and plipastatin (fengycin family) are sensed by grapevine plant cells (Farace et al., 2015). Although surfactin and mycosubtilin stimulate grapevine innate immune responses, they differentially activate early signaling pathways and defense marker genes. Plipastatin perception by grapevine cells only results in early signaling activation. Gene expression analysis suggested that mycosubtilin activates SA and JA signaling pathways, whereas surfactin mainly induces SA signaling. Interestingly, only surfactin and mycosubtilin treatments result in a local IR against $B$. cinerea in grapevine leaves. Challenge with specific B. subtilis strains overproducing surfactin and mycosubtilin also led to a slightly enhanced stimulation of grapevine defense responses compared with a wild-type strain of the bacteria (Farace et al., 2015). B. subtilis strain GLB191 confers protection to grapevine against downy mildew in controlled conditions and in the vineyard (Zhang et al., 2017). Recently, GLB191 supernatant was shown to be also highly active, with a double effect: oomycide and defense elicitor (Li et al., 2019). The supernatants of GLB191 mutants affected in the production of fengycin and/or surfactin loose partial or total activity, suggesting that both LPs contribute to the activity of GLB191 supernatant against downy mildew. As for RLs, the recognition mechanism of LPs is not fully understood. Mycosubtilin and fengycin are known to interact with biomimetic membrane lipids, in particular with phospholipids and sterols (MagetDana and Ptak, 1990; Deleu et al., 2005, Deleu et al., 2008). 
Studies on surfactin showed that the LP structure strongly impacts the immune response (Jourdan et al., 2009). The reduced activity of some surfactin homologues indicates that surfactin perception is dictated by structural clues in both the acyl moiety and cyclic peptide parts. Surfactin immune signatures suggest that these molecules could interact with membranes without irreversible pore formation but in a way sufficient to induce disturbance or transient channeling in the plasma membrane. This phenomenon could, in turn, activate a biochemical cascade of molecular events leading to defensive responses (Jourdan et al., 2009). Surfactins with long chains are more effective than the shortest ones. Repeated challenges with surfactin do not result in a refractory state (desensitization), suggesting that the sensing of the molecule does not involve a high-affinity protein receptor (Henry et al., 2011). Moreover, surfactin is able to target the lipid fraction of the plant plasma membrane, and long-chain surfactins are more active. Altogether, as for RLs, it is proposed that the recognition of these amphiphilic elicitors could rely on a lipid-driven process, leading to the perturbation of the membrane structure, and resulting in the activation of the immune response. Interestingly, this lipid-driven process seems to be less specific than the perception by PRRs as it could take place in several plant species, including grapevine. However, a dichotomy between monocots and dicots cannot be excluded as it has been shown for the perception of the toxin necrosis and ethylene-inducing peptide 1-like protein (NLP) by sphingolipid receptors (Lenarčič et al., 2017).

\section{Sulfation of the Laminarin $\beta$-Glucan Improves Its Resistance-Inducing Activity}

The eliciting activity of the $\beta$-glucan oligosaccharides laminarin and its sulfated derivative PS3 have been studied in details. Laminarin is naturally produced by the brown algae Laminaria digitata and is a reserve carbohydrate of oomycetes (Bacic et al., 2009). It has an average DP of 25-33 glucose units and up to three single $\beta$-glucose branches at position 6 (Klarzynski et al., 2000). PS3 (phycarin sulfated 3) was obtained by chemical sulfation of laminarin and has a degree of sulfation of 2.4 (Ménard et al., 2004). In plants and mammals, the presence of sulfates is crucial for the biological activity of oligosaccharides, suggesting that chemical sulfation of oligosaccharides can improve their biological properties. Studies conducted with tobacco plants reported that, compared to laminarin, its sulfated derivative PS3 triggers a stronger immunity against tobacco mosaic virus (Ménard et al., 2004). Similarly, PS3 induces a stronger grapevine resistance against $P$. viticola compared to laminarin (Gauthier et al., 2014). In tobacco, Klarzynski et al. (2000) have shown that, while laminarin elicits phenylalanine ammonia lyase (PAL) activity, di-, tri-, and tetramers of $\beta$-1,3-glucan are inactive. In a structure-activity analysis, Ménard et al. (2004) demonstrated that the sulfate residues and a minimum $\beta$-1,3-glucan chain length (DP 5) are essential for PS3 activity in tobacco. Interestingly, PS3 and laminarin differ by their capacity to trigger (i) early grapevine defense responses and (ii) a stress-responsive transcriptome. Indeed, conversely to laminarin that elicits canonical early responses like cytosolic $\left[\mathrm{Ca}^{2+}\right]$ variations, $\mathrm{H} 2 \mathrm{O} 2$ production, MAPK activation, and plasma membrane depolarization, PS3 only induces a long-lasting plasma membrane depolarization. Furthermore, transcriptional changes observed in response to both $\beta$-1,3-glucans present similarities but differ in the intensity of transcriptome expression. Indeed, several genes are up-regulated by both $\beta$-1,3-glucans, but PS3 triggers a variation in the global transcriptional reprogramming 3.9fold higher (Gauthier et al., 2014). Among the genes induced by PS3, many genes encode proteins involved in carbohydrate catabolism providing energetic nucleotides (e.g., ATP) and reduced cofactors (e.g., NADH and NADPH). These cofactors are particularly important for the activity of enzymes involved in defense responses. For instance, the NADPH is used by the respiratory burst oxidase homologue $(\mathrm{RBOH})$ to produce an intense ROS production at the site of pathogen infection (Gauthier et al., 2014). This observation might also explain why sulfation of laminarin improved laminarin-IR against P. viticola in grapevine, with a HR-like profile (Trouvelot et al., 2008). Moreover, our results revealed that, compared to laminarin, PS3-IR against $P$. viticola in grapevine was correlated with the priming of defense genes, SA and $\mathrm{H} 2 \mathrm{O} 2$ productions, callose deposition, and HR-like cell death. These various responses have been shown to be dependent on anionic channel activity (Gauthier et al., 2014). This activity has already been demonstrated to play key role in the establishment of the HR in tobacco (Wendehenne et al., 2002; Gauthier et al., 2007).

To assess whether PS3 and laminarin are perceived by a common receptor, $\mathrm{H} 2 \mathrm{O} 2$ production assay was used to determine whether successive additions of PS3 and laminarin would result in a desensitized state. As expected, grapevine cells treated twice with laminarin were unable to respond to the second treatment (Figure 2B). Interestingly, the pretreatment with PS3 prevented grapevine cells to respond to the subsequent addition of laminarin (Figure 2B). These data suggest that PS3 and laminarin are recognized by a common receptor and that sulfation of laminarin elicits the activation of different signaling cascades, leading to an enhanced immunity correlated to a higher resistance. Recently, the non-branched $\beta$-1,3-glucan hexamer has been shown to trigger Arabidopsis immune responses which were impaired in the cerk1 mutant, suggesting that CERK1 might be a co-receptor for the $\beta$-1,3glucan perception in this plant species (Mélida et al., 2018).

\section{DISCUSSION}

\section{Finding New VvPRRs and Investigating Their Spatiotemporal Expression in Grapevine}

As described above, several elicitors of different nature, MAMPs or DAMPs, have been shown so far to efficiently induce immune responses in grapevine. Nevertheless, the discovery of grapevine PRRs began only recently and 
some information are still missing to fully understand the mechanisms of perception of these elicitors by grapevine cells. Based on the actual knowledge in Arabidopsis, it is highly probable that a grapevine ortholog for BRASSINOSTEROIDINSENSITIVE 1-ASSOCIATED RECEPTOR KINASE 1 (VvBAK1) co-receptor might also exist in grapevine to form the functional receptor complex with the flg22 receptor VvFLS2 (Figure 1). Similarly, a co-receptor of the AtCERK1/ LYK1 orthologues VvLYK1-1 and VvLYK1-2 might also exist in grapevine. However, the bioinformatics predictions are more complicated because the grapevine genome contains two putative genes encoding orthologs of the rice OsCEBIP. Moreover, grapevine possesses 13 other genes encoding putative VvLYKs, the function of which is still unknown and including two orthologues of the Arabidopsis AtLYK5, known as the high-affinity binding domain of the chitin receptor complex (Cao et al., 2014). Interestingly, the expression of $V v C E B I P 1$ is induced by chitin treatment in grapevine cells (Trdá, 2014), while two VvLYK5 genes are induced by the necrotrophic fungus $B$. cinerea during berry infection (Brulé et al., 2019). Concerning the $B$. cinerea PGs, the production of recombinant $\mathrm{BcPG} 1$ in the heterologous system Pichia pastoris was not very efficient (Kars et al., 2005), thus rendering the identification of its cognate receptor in grapevine very difficult. Nevertheless, since the Arabidopsis receptor complex involves a RLP named RBPG1 and its co-receptor the RLK SOBIR1 (Zhang et al., 2014) and given the role of SOBIR1 as important co-receptor of many RLPs (Gust and Felix, 2014), the investigation of its grapevine ortholog definitively deserves attention. Lastly, the grapevine genome contains at least one clear orthologue gene of the OG receptor WAK1, which is induced during infection of grapevine flowers with B. cinerea (Haile et al., 2017). For all these PRR candidates, the development of genome editing by CRISPR-Cas9 could be a very useful technology to test the function of these putative orthologs through a loss-of-function approach in grapevine. The recent evidences that this technology can be efficiently used in this crop opens promising perspectives (Wang et al., 2018).

This fundamental knowledge will be important to better apply MAMPs/DAMPs to induce grapevine resistance, particularly in vineyards. Indeed, some biocontrol products are now homologated in the vineyards, such as the COS-OGA (van Aubel et al., 2014). However, are these elicitors actually perceived by the plant in natural conditions? This open question is of particular importance considering a perennial crop, which will require a deep investigation of the expression of the different immune receptors at different phenological stages and in different organs and taking plant aging into account. Since PRR-mediated immune responses vary during plant development (Zou et al., 2018), it would be interesting to know for instance if VvLYK1 and VvWAK1, two receptors involved in COS-OGA perception, are expressed in young leaves and flowers, two organs that are highly susceptible to filamentous microbes (Figure 3). Moreover, we must keep in mind the importance of plant genotypes (Figure 3) as the grapevine cultivars can differently respond to treatment with the same resistance inducers (Banani et al., 2014). In Arabidopsis, it has been shown that the existing natural mutations are sufficient to explain that some genotypes are

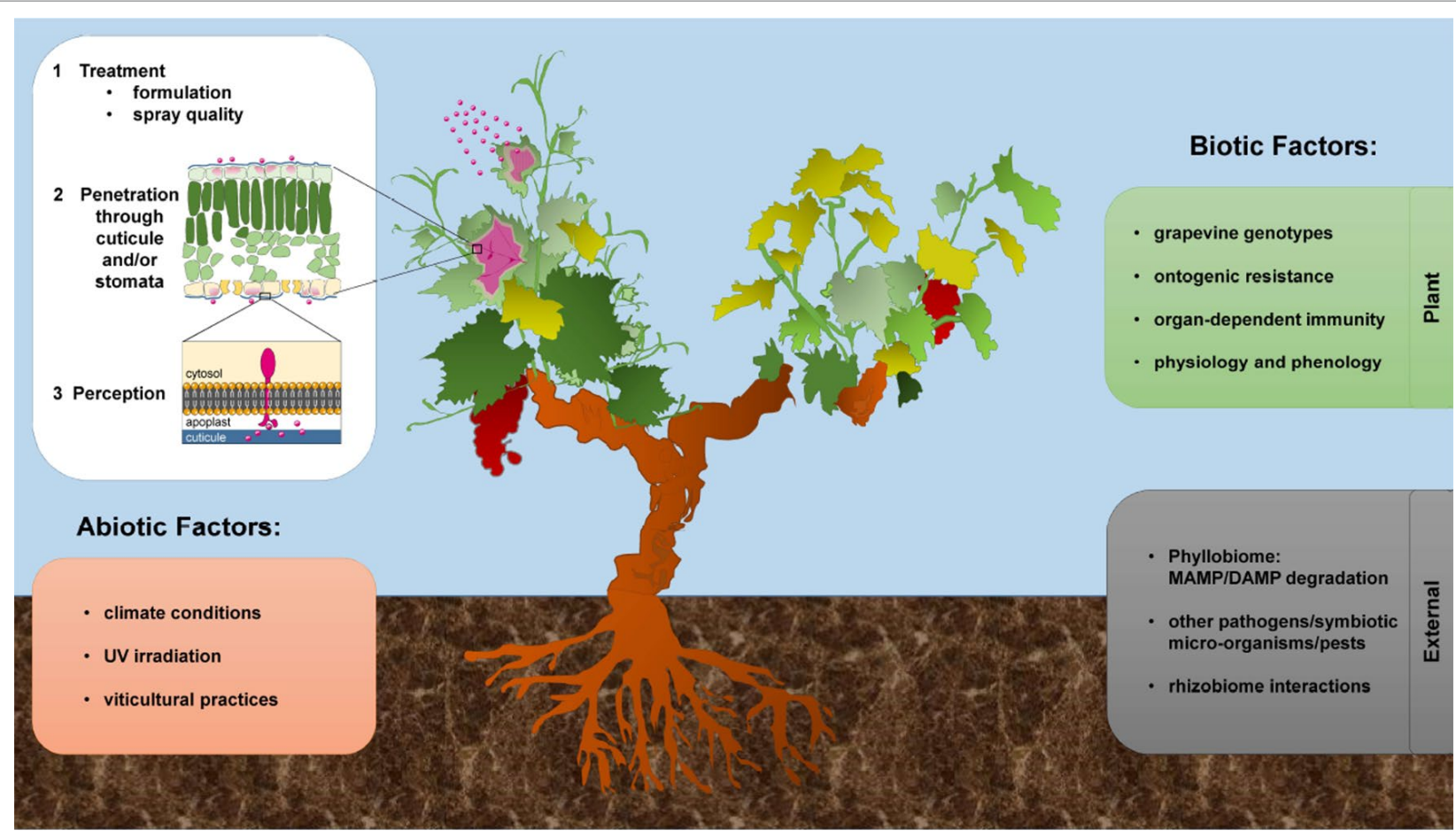

FIGURE 3 | Effect of different factors influencing grapevine induced resistance in vineyards. 
totally unable to sense MAMPs as flg22 (Felix et al., 1999; Zipfel et al., 2004; Vetter et al., 2012). This supports the need for a better knowledge of the molecular mechanisms to ensure a broad and durable action of elicitors as resistance inducers in grapevine.

\section{Searching for Effective IR Markers}

Concerning MAMPs/DAMPs, the screening of active biomolecules must continue to identify new resistance inducers and develop their use in crop protection strategies. However, the stimulation of the immune system is not systematically correlated with IR. Hence, from an applicative point of view, it is necessary to identify effective IR markers. It was for this purpose that a comparative experiment was performed with two oligosaccharidic elicitors differing in their capacity of inducing resistance against $P$. viticola: one effective (PS3) and one non-effective (a short laminarin of DP 13 that triggers production of $\mathrm{H} 2 \mathrm{O} 2$ without inducing any protection). On one hand, proteomics showed that only few proteins, including the 12-oxophytodienoate reductase (OPR-like) related to the OPDA pathway and an arsenite-resistance protein (serrate-like protein), were found as possible markers of PS3-IR (LemaîtreGuillier et al., 2017). On the other hand, metabolomics analysis highlighted erythritol phosphate, a phosphorylated polyol, as another possible marker of PS3-IR. In parallel, the microarray analysis showed that the PS3-induced transcriptomic profile includes genes encoding a SA methyl transferase and terpene synthases (Gauthier, 2009; Gauthier et al., 2014). Further investigation of the emission of volatile organic compounds (VOCs) in grapevine plants treated with PS3 showed the production of mono- and sesquiterpenes, notably trans- $\beta$ ocimene and (E-E) $\alpha$-farnesene (Chalal et al., 2015). Altogether, these experiments revealed a rather limited number of putative IR markers, and we cannot rule out the possibility that IR markers would differ with other resistance inducers or in other genotypes. It will therefore be probably more reasonable to consider "metabolic signatures" of effective resistance markers rather than a specific one. In this context, the non-destructive monitoring of VOCs may become a convenient way to study the plant response to resistance inducers in the field.

\section{Factors Influencing Efficient Grapevine IR in Vineyards}

Polysaccharides and lipids are particularly interesting because many of them are approved for human feeding, and their costs of production are compatible with an application in viticulture. However, in field conditions, it is clear that only few elicitors, proved to be effective to induce resistance in controlled conditions, maintain their performances (Delaunois et al., 2014). Besides the above-mentioned lack of knowledge of elicitor recognition in natural conditions, the effectiveness of elicitor induced-resistance depends also on several biotic and abiotic factors (Figure 3). First, the active molecules must penetrate the plant tissues to elicit innate immunity. For oligosaccharidic elicitors (e.g., laminarin or PS3), the main barrier is represented by the cuticle, which is difficult to cross due to high hydrophobicity, and also generally thicker in field conditions. Using a fluorescently tagged PS3, it was shown how compound formulation is important for improving the bioavailability of certain elicitors (hydrophilic) and, consequently, their effectiveness to induce resistance (Paris et al., 2016). Such works also showed that the stomata, present in grapevine almost exclusively on the underside of the leaves, represent an important entry route for these treatments. Finally, it is nevertheless possible to improve the penetration of hydrophilic elicitors by (i) an ad hoc formulation with surfactants, and/or (ii) targeting a spray on the more permeable lower leaf surface (Figure 3).

The stability of the applied elicitors is another understudied aspect to consider for plant protection. Indeed, elicitors could be degraded after application, notably by plant microbiome (Trouvelot et al., 2014). For instance, laminarin is a substrate for $\beta$-1,3-glucanases. Thus, a basal activity of microbial or plant glucanases could degrade laminarin and, consequently, releases short inactive $\beta$-glucans. This biodegradation of elicitors might be very rapid in natural conditions and may partly explain the lower efficiency of these resistance inducers in vineyards (Figure 3). Interestingly, laminarin sulfation clearly protects the molecule from its enzymatic degradation, thus increasing its stability (Ménard et al., 2005) and probably explaining the higher resistance induced by PS3 compared to laminarin (Gauthier et al., 2014). In the same way, plant enzymes such as the BBE-like proteins play a crucial role in controlling the elicitor activity of oligosaccharides. According to their oxidase function dampening the excessive accumulation of active OGs and CDs (Benedetti et al., 2018; Locci et al., 2019), we could assume that such plant enzymatic activities may interfere with oligosaccharide stability as active elicitors. Moreover, in Arabidopsis, BBE-like proteins constitute a family of 28 members, and so far, only 5 of them have been demonstrated to be involved in the DAMP-homeostasis (OGs and CDs). The remaining uncharacterized members of this family might be responsible for the inactivation of "orphan" cell-wall-derived DAMPs, such as xyloglucans or the less characterized "Burdock" fructo-oligosaccharides (Sun et al., 2013). The identification of the BBE-like protein family in Vitis vinifera should also be investigated for a better knowledge of oligosaccharide defense induction in grapevine and their possible application. Other environmental factors must also be taken into account, such as molecule degradation by intense UV light, washing by rain falls or a rapid drying preventing the penetration of the elicitors through the cuticle (Figure 3 ). Therefore, the formulation of these new biocontrol products must be optimized to ensure molecule stability in changing conditions and allow their rapid penetration through cuticle and cell wall.

Finally, many other factors, such as viticultural practices or interactions with the plant-associated microbiomes, could impact the plant physiology which is determinant to mount an efficient IR in field conditions. 


\section{AUTHOR CONTRIBUTIONS}

M-CH, MA, DB, JC, SC, XD, SD, AG, CL-G, JN, LT, ST, EV and $\mathrm{BP}$ contribute together to the writing of this review.

\section{FUNDING}

M-CH, MA, DB, JC, SC, XD, SD, AG, CL-G, JN, LT, ST, EV and $\mathrm{BP}$ have been financially supported by ANR, Feder, the Regional Council of Bourgogne Franche-Comté and the Bureau Interprofessionnel des Vins de Bourgogne. SD, SC, ST, $\mathrm{M}-\mathrm{CH}, \mathrm{CL}-\mathrm{G}, \mathrm{MA}$ and BP have been supported by the MESRI

\section{REFERENCES}

Adrian, M., Trouvelot, S., Gamm, M., Poinssot, B., Héloir, M. C., and Daire, X., (2012). "Activation of grapevine defense mechanisms: theoretical and applied approaches," in Progress in biological control, plant defence: biological control, vol. 12. Ed. J. M. K. Ramawat (Dordrecht: Springer), 313-331. doi: 10.1007/978-94-007-1933-0_13

Ait Barka, E., Belarbi, A., Hachet, C., Nowak, J., and Audran, J. (2000). Enhancement of in vitro growth and resistance to gray mould of Vitis vinifera co-cultured with plant growth-promoting rhizobacteria. FEMS Microbiol. Lett. 186, 91-95. doi: 10.1111/j.1574-6968.2000.tb09087.x

Ait Barka, E., Nowak, J., and Clement, C. (2006). Enhancement of chilling resistance of inoculated grapevine plantlets with a plant growth-promoting rhizobacterium, Burkholderia phytofirmans strain PsJN. Appl. Environ. Microbiol. 72, 7246-7252. doi: 10.1128/AEM.01047-06

Alexandrova, M., Bazzi, C., and Holst, O. (2000). Protective effect of bacterial lipopolysaccharides in the grapevine-Agrobacterium vitis interaction. Vitis 39, 67-70.

Aziz, A., Gauthier, A., Bezler, A., Poinssot, B., Joubert, J. M., Pugin, A., et al. (2007). Elicitor and resistance-inducing activities of beta-1,4 cellodextrins in grapevine, comparison with beta-1,3 glucans and alpha-1,4 oligogalacturonides. J. Exp. Bot. 58, 1463-1472. doi: 10.1093/jxb/erm008

Aziz, A., Poinssot, B., Daire, X., Adrian, M., Bezier, A., Lambert, B., et al. (2003). Laminarin elicits defense responses in grapevine and induces protection against Botrytis cinerea and Plasmopara viticola. Mol. Plant-Microbe Interact. 16, 1118-1128. doi: 10.1094/MPMI.2003.16.12.1118

Aziz, A., Trotel-Aziz, P., Dhuicq, L., Jeandet, P., Couderchet, M., and Vernet, G. (2006). Chitosan oligomers and copper sulfate induce grapevine defense reactions and resistance to gray mold and downy mildew. Phytopathology 96, 1188-1194. doi: 10.1094/PHYTO-96-1188

Bacic, A., Fincher, G. B., and Stone, B. A., (2009). Chemistry, biochemistry, and biology of 1-3 beta glucans and related polysaccharides. (Elsevier, Burlington,. MA, USA: Academic Press).

Baker, L. G., Specht, C. A., Donlin, M. J., and Lodge, J. K. (2007). Chitosan, the deacetylated form of chitin, is necessary for cell wall integrity in Cryptococcus neoformans. Eukaryot Cell 6, 855-867. doi: 10.1128/EC.00399-06

Banani, H., Roatti, B., Ezzahi, B., Giovannini, O., Gessler, G., Pertot, I., et al. (2014). Characterization of resistance mechanisms activated by Trichoderma harzianum T39 and benzothiadiazole to downy mildew in different grapevine cultivars. Plant Pathol. 63, 334-343. doi: 10.1111/ppa.12089

Barber, M. S., Bertram, R. E., and Ride, J. P. (1989). Chitin oligosaccharides elicit lignification in wounded wheat leaves. Physiol. Mol. Plant Pathol. 34, 3-12. doi: 10.1016/0885-5765(89)90012-X

Bauer, Z., Gomez-Gomez, L., Boller, T., and Felix, G. (2001). Sensitivity of different ecotypes and mutants of Arabidopsis thaliana toward the bacterial elicitor flagellin correlates with the presence of receptor-binding sites. J. Biol. Chem. 276, 45669-45676. doi: 10.1074/jbc.M102390200

Benedetti, M., Pontiggia, D., Raggi, S., Cheng, Z., Scaloni, F., Ferrari, S., et al. (2015). Plant immunity triggered by engineered in vivo release of oligogalacturonides, damage-associated molecular patterns. Proc. Natl. Acad. Sci. U. S. A. 112, $5533-$ 5538. doi: 10.1073/pnas.1504154112
(Ministère de l'Enseignement Supérieur, de la Recherche et de l'Innovation).

\section{ACKNOWLEDGMENTS}

We thank Agnès Klinguer, Lucile Jacquens, Elodie Noirot and Annick Chiltz for excellent technical assistance. We would like to thank Freddy Boutrot for critical readings and text editing. The Federative Research Structure "SFR Condorcet" is also greatly acknowledged. Figure $\mathbf{2 A}$ was first published in the thesis of Benoit Poinssot (2002). Figure 2B was first published in the thesis of Adrien Gauthier (2009).

Benedetti, M., Verrascina, I., Pontiggia, D., Locci, F., Mattei, B., De Lorenzo, G., et al. (2018). Four Arabidopsis berberine bridge enzyme-like proteins are specific oxidases that inactivate the elicitor-active oligogalacturonides. Plant J. 94, 260-273. doi: 10.1111/tpj.13852

Berry, M. C., McGhee, G. C., Zhao, Y., and Sundin, G. W. (2009). Effect of a waaL mutation on lipopolysaccharide composition, oxidative stress survival, and virulence in Erwinia amylovora. FEMS Microbiol. Lett. 291, 80-87. doi: 10.1111/j.1574-6968.2008.01438.x

Binet, M. N., Bourque, S., Lebrun-Garcia, A., Chiltz, A., and Pugin, A. (1998). Comparison of the effects of cryptogein and oligogalacturonides on tobacco cells and evidence of different forms of desensitization induced by these elicitors. Plant Sci. 137, 33-41. doi: 10.1016/S0168-9452(98)00132-0

Boller, T., and Felix, G. (2009). A renaissance of elicitors: perception of microbeassociated molecular patterns and danger signals by pattern-recognition receptors. Annu. Rev. Plant Biol. 60, 379-406. doi: 10.1146/annurev. arplant.57.032905.105346

Bordiec, S., Paquis, S., Lacroix, H., Dhondt, S., Ait Barka, E., Kauffmann, S., et al. (2011). Comparative analysis of defence responses induced by the endophytic plant growth-promoting rhizobacterium Burkholderia phytofirmans strain PsJN and the non-host bacterium Pseudomonas syringae pv. pisi in grapevine cell suspensions. J. Exp. Bot. 62, 595-603. doi: 10.1093/jxb/erq291

Boutrot, F., and Zipfel, C. (2017). Function, discovery, and exploitation of plant pattern recognition receptors for broad-spectrum disease resistance. Annu. Rev. Phytopathol. 55, 257-286. doi: 10.1146/annurev-phyto-080614-120106

Bozsoki, Z., Cheng, J., Feng, F., Gysel, K., Vinther, M., Andersen, K. R., et al. (2017). Receptor-mediated chitin perception in legume roots is functionally separable from Nod factor perception. Proc. Natl. Acad. Sci. U. S. A. 114, E8118-E8127. doi: 10.1073/pnas.1706795114

Braun, S. G., Meyer, A., Holst, O., Pühler, A., and Niehaus, K. (2005). Characterization of the Xanthomonas campestris $p v$. campestris lipopolysaccharide substructures essential for elicitation of an oxidative burst in tobacco cells. Mol. Plant Microbe Interact. 18, 674-681. doi: 10.1094/MPMI-18-0674

Brulé, D., Villano, C., Davies, L. J., Trdá, L., Claverie, J., Héloir, M. C., et al. (2019). The grapevine (Vitis vinifera) LysM receptor kinases VvLYK1-1 and VvLYK1-2 mediate chitooligosaccharide-triggered immunity. Plant Biotechnol. J. 17, 812-825. doi: 10.1111/pbi.13017

Brutus, A., Sicilia, F., Macone, A., Cervone, F., and De Lorenzo, G. (2010). A domain swap approach reveals a role of the plant wall-associated kinase 1 (WAK1) as a receptor of oligogalacturonides. Proc. Natl. Acad. Sci. U. S. A. 107, 9452-9457. doi: 10.1073/pnas.1000675107

Cabrera, J. C., Boland, A., Messiaen, J., Cambier, P., and Van Cutsem, P. (2008). Egg box conformation of oligogalacturonides: the time-dependent stabilization of the elicitor-active conformation increases its biological activity. Glycobiology 18, 473-482. doi: 10.1093/glycob/cwn027

Cao, Y., Liang, Y., Tanaka, K., Nguyen, C. T., Jedrzejczak, R. P., Joachimiak, A., et al. (2014). The kinase LYK5 is a major chitin receptor in Arabidopsis and forms a chitin-induced complex with related kinase CERK1. Elife 3, 03766. doi: 10.7554/eLife.03766

Caroff, M., and Karibian, D. (2003). Structure of bacterial lipopolysaccharides. Carbohydr. Res. 338, 2431-2447. doi: 10.1016/j.carres.2003.07.010 
Casida, J. E. (2009). Pest toxicology: the primary mechanisms of pesticide action. Chem. Res. Toxicol. 22, 609-619. doi: 10.1021/tx8004949

Cervone, F., De Lorenzo, G., Degrà, L., and Salvi, G. (1987). Elicitation of necrosis in Vigna unguiculata Walp. by homogeneous Aspergillus niger endopolygalacturonase and by alpha-d-galacturonate oligomers. Plant Physiol. 85, 626-630. doi: 10.1104/pp.85.3.626

Chalal, M., Winkler, J. B., Gourrat, K., Trouvelot, S., Adrian, M., Schnitzler, J. P., et al. (2015). Sesquiterpene volatile organic compounds (VOCs) are markers of elicitation by sulfated laminarine in grapevine. Front. Plant Sci. 6, 350. doi: 10.3389/fpls.2015.00350

Chinchilla, D., Bauer, Z., Regenass, M., Boller, T., and Felix, G. (2006). The Arabidopsis receptor kinase FLS2 binds flg22 and determines the specificity of flagellin perception. Plant Cell 18, 465-476. doi: 10.1105/tpc.105.036574

Claverie, J., Balacey, S., Lemaître-Guillier, C., Brulé, D., Chiltz, A., Granet, L., et al. (2018). The cell wall-derived xyloglucan is a new DAMP triggering plant immunity in Vitis vinifera and Arabidopsis thaliana. Front. Plant Sci. 9, 1725. doi: 10.3389/fpls.2018.01725

Clifford, J. C., Rapicavoli, J. N., and Roper, M. C. (2013). A rhamnoserich $\mathrm{O}$-antigen mediates adhesion, virulence, and host colonization for the xylem-limited phytopathogen Xylella fastidiosa. Mol. Plant Microbe Interact. 26, 676-685. doi: 10.1094/MPMI-12-12-0283-R

Compant, S., Reiter, B., Sessitsch, A., Nowak, J., Clement, C., and Ait Barka, E. (2005). Endophytic colonization of Vitis vinifera L. by plant growth promoting bacterium Burkholderia sp strain PsJN. Appl. Environ. Microbiol. 71, 16851693. doi: 10.1128/AEM.71.4.1685-1693.2005

Conrath, U. (2011). Molecular aspects of defence priming. Trends Plant Sci. 16, 524-531. doi: 10.1016/j.tplants.2011.06.004

Conrath, U., Beckers, G. J. M., Flors, V., Garcia-Agustin, P., Jakab, G., Mauch, F., et al. (2006). Priming: getting ready for battle. Mol. Plant-Microbe Interact. 19, 1062-1071. doi: 10.1094/MPMI-19-1062

Davidsson, P., Broberg, M., Kariola, T., Sipari, N., Pirhonen, M., and Palva, E. T. (2017). Short oligogalacturonides induce pathogen resistance-associated gene expression in Arabidopsis thaliana. BMC Plant Biol. 17, 19. doi: 10.1186/ s12870-016-0959-1

Decreux, A., Thomas, A., Spies, B., Brasseur, R., Van Cutsem, P., and Messiaen, J. (2006). In vitro characterization of the homogalacturonan-binding domain of the wall-associated kinase WAK1 using site-directed mutagenesis. Phytochemistry 67, 1068-1079. doi: 10.1016/j.phytochem.2006.03.009

Delaunois, B., Farace, G., Jeandet, P., Clément, C., Baillieul, F., Dorey, S., et al. (2014). Elicitors as alternative strategy to pesticides in grapevine? Current knowledge on their mode of action from controlled conditions to vineyard. Environ. Sci. Pollut. Res. Int. 21, 4837-4846. doi: 10.1007/s11356-013-1841-4

Deleu, M., Paquot, M., and Nylander, T. (2005). Fengycin interaction with lipid monolayers at the air-aqueous interface-implications for the effect of fengycin on biological membranes. J. Colloid Interface Sci. 283, 358-365. doi: 10.1016/j. jcis.2004.09.036

Deleu, M., Paquot, M., and Nylander, T. (2008). Effect of fengycin, a lipopeptide produced by Bacillus subtilis, on model biomembranes. Biophys. J. 94, 26672679. doi: 10.1529/biophysj.107.114090

Delteil, A., Gobbato, E., Cayrol, B., Estevan, J., Michel-Romiti, C., Dievart, A., et al. (2016). Several wall-associated kinases participate positively and negatively in basal defense against rice blast fungus. BMC Plant Biol. 16, 17. doi: 10.1186/ s12870-016-0711-x

Denoux, C., Galletti, R., Mammarella, N., Gopalan, S., Werck, D., De Lorenzo, G., et al. (2008). Activation of defense response pathways by OGs and Flg22 elicitors in Arabidopsis seedlings. Mol. Plant 1, 423-445. doi: 10.1093/mp/ssn019

Derckel, J. P., Baillieul, F., Manteau, S., Audran, J. C., Haye, B., Lambert, B., et al. (1999). Differential induction of grapevine defenses by two strains of Botrytis cinerea. Phytopathology 89, 197-203. doi: 10.1094/PHYTO.1999.89.3.197

Desaki, Y., Kouzai, Y., Ninomiya, Y., Iwase, R., Shimizu, Y., Seko, K., et al. (2018). OsCERK1 plays a crucial role in the lipopolysaccharide-induced immune response of rice. New Phytol. 217, 1042-1049. doi: 10.1111/nph.14941

Desaki, Y., Miya, A., Venkatesh, B., Tsuyumu, S., Yamane, H., Kaku, H., et al. (2006). Bacterial lipopolysaccharides induce defense responses associated with programmed cell death in rice cells. Plant Cell Physiol. 47, 1530-1540. doi: $10.1093 / \mathrm{pcp} / \mathrm{pcl} 019$

Di Lorenzo, F., Palmigiano, A., Silipo, A., Desaki, Y., Garozzo, D., Lanzetta, R., et al. (2016). The structure of the lipooligosaccharide from Xanthomonas oryzae $p$.
Oryzae: the causal agent of the bacterial leaf blight in rice. Carbohydr. Res. 427, 38-43. doi: 10.1016/j.carres.2016.03.026

Diener, A. C., and Ausubel, F. M. (2005). Resistance To Fusarium Oxysporum 1, a dominant Arabidopsis disease-resistance gene, is not race specific. Genetics 171, 305-321. doi: 10.1534/genetics.105.042218

dos Santos, H. P., Purgatto, E., Mercier, H., and Buckeridge, M. S. (2004). The control of storage xyloglucan mobilization in cotyledons of Hymenaea courbaril. Plant Physiol. 135, 287-299. doi: 10.1104/pp.104.040220

El Hadrami, A., Adam, L. R., El Hadrami, I., and Daayf, F. (2010). Chitosan in plant protection. Mar. Drugs 8, 968-987. doi: 10.3390/md8040968

Enkerli, J., Felix, G., and Boller, T. (1999). The enzymatic activity of fungal xylanase is not necessary for its elicitor activity. Plant Physiol. 121, 391-397. doi: $10.1104 /$ pp.121.2.391

Farace, G., Fernandez, O., Jacquens, L., Coutte, F., Krier, F., Jacques, P., et al. (2015). Cyclic lipopeptides from Bacillus subtilis activate distinct patterns of defence responses in grapevine. Mol. Plant Pathol. 16, 177-187. doi: 10.1111/ mpp. 12170

Felix, G., Duran, J. D., Volko, S., and Boller, T. (1999). Plants have a sensitive perception system for the most conserved domain of bacterial flagellin. Plant $J$. 18, 265-276. doi: 10.1046/j.1365-313X.1999.00265.x

Fernandez, O., Theocharis, A., Bordiec, S., Feil, R., Jacquens, L., Clement, C., et al. (2012). Burkholderia phytofirmans PsJN acclimates grapevine to cold by modulating carbohydrate metabolism. Mol. Plant-Microbe Interact. 25, 496504. doi: 10.1094/MPMI-09-11-0245

Ferrari, S., Galletti, R., Denoux, C., De Lorenzo, G., Ausubel, F. M., and Dewdney, J. (2007). Resistance to Botrytis cinerea induced in Arabidopsis by elicitors is independent of salicylic acid, ethylene, or jasmonate signaling but requires Phytoalexin Deficient3. Plant Physiol. 144, 367-379. doi: 10.1104/ pp.107.095596

Fry, S. C., Aldington, S., Hetherington, P. R., and Aitken, J. (1993). Oligosaccharides as signals and substrates in the plant cell wall. Plant Physiol. 103, 1-5. doi: 10.1104/pp.103.1.1

Furman-Matarasso, N., Cohen, E., Du, Q., Chejanovsky, N., Hanania, U., and Avni, A. (1999). A point mutation in the ethylene-inducing xylanase elicitor inhibits the beta-1-4-endoxylanase activity but not the elicitation activity. Plant Physiol. 121, 345-351. doi: 10.1104/pp.121.2.345

Galletti, R., Denoux, C., Gambetta, S., Dewdney, J., Ausubel, F. M., De Lorenzo, G., et al. (2008). The AtrbohD-Mediated oxidative burst elicited by oligogalacturonides in Arabidopsis is dispensable for the activation of defense responses effective against Botrytis cinerea. Plant Physiol. 148, 1695-1706. doi: 10.1104/ pp.108.127845

Galletti, R., Ferrari, S., and De Lorenzo, G. (2011). Arabidopsis MPK3 and MPK6 play different roles in basal and oligogalacturonide- or flagellin-induced resistance against Botrytis cinerea. Plant Physiol. 157, 804-814. doi: 10.1104/ pp.111.174003

Garcia-Brugger, A., Lamotte, O., Vandelle, E., Bourque, S., Lecourieux, D., Poinssot, B., et al. (2006). Early signaling events induced by elicitors of plant defenses. Mol. Plant-Microbe Interact. 19, 711-724. doi: 10.1094/ MPMI-19-0711

Gauthier, A. (2009). Comparaison de différents éliciteurs des réactions de défense de la vigne: étude du mode d'action de la laminarine sulfatée, un inducteur de résistance à P. viticola. PhD Thesis. Dijon (F): Univ. Bourgogne.

Gauthier, A., Lamotte, O., Reboutier, D., Bouteau, F., Pugin, A., and Wendehenne, D. (2007). Cryptogein-induced anion effluxes: electrophysiological properties and analysis of the mechanisms through which they contribute to the elicitor-triggered cell death. Plant Signal Behav. 2, 86-95. doi: 10.4161/ psb.2.2.4015

Gauthier, A., Trouvelot, S., Kelloniemi, J., Frettinger, P., Wendehenne, D., Daire, X., et al. (2014). The sulfated laminarin triggers a stress transcriptome before priming the SA- and ROS-dependent defenses during grapevine's induced resistance against Plasmopara viticola. PLoS One 9, e88145. doi: 10.1371/ journal.pone. 0088145

Gimenez-Ibanez, S., Ntoukakis, V., and Rathjen, J. P. (2009). The LysM receptor kinase CERK1 mediates bacterial perception in Arabidopsis. Plant Signal Behav. 4, 539-541. doi: 10.4161/psb.4.6.8697

Gomez-Gomez, L., and Boller, T. (2000). FLS2: An LRR receptor-like kinase involved in the perception of the bacterial elicitor flagellin in Arabidopsis. Mol. Cell 5, 1003-1011. doi: 10.1016/S1097-2765(00)80265-8 
Gramegna, G., Modesti, V., Savatin, D. V., Sicilia, F., Cervone, F., and De Lorenzo, G. (2016). GRP-3 and KAPP, encoding interactors of WAK1, negatively affect defense responses induced by oligogalacturonides and local response to wounding. J. Exp. Bot. 67, 1715-1729. doi: 10.1093/jxb/erv563

Gust, A. A., and Felix, G. (2014). Receptor like proteins associate with SOBIR1type of adaptors to form bimolecular receptor kinases. Curr. Opin. Plant Biol. 21, 104-111. doi: 10.1016/j.pbi.2014.07.007

Hadwiger, L. A. (2013). Multiple effects of chitosan on plant systems: solid science or hype. Plant Sci. 208, 42-49. doi: 10.1016/j.plantsci.2013.03.007

Haile, Z. M., Pilati, S., Sonego, P., Malacarne, G., Vrhovsek, U., Engelen, K., et al. (2017). Molecular analysis of the early interaction between the grapevine flower and Botrytis cinerea reveals that prompt activation of specific host pathways leads to fungus quiescence. Plant Cell Environ. 40, 1409-1428. doi: $10.1111 /$ pce. 12937

Harkenrider, M., Sharma, R., De Vleesschauwer, D., Tsao, L., Zhang, X., Chern, M., et al. (2016). Overexpression of rice wall-associated kinase 25 (OsWAK25) alters resistance to bacterial and fungal pathogens. PLoS One 11, e0147310. doi: 10.1371/journal.pone.0147310

Hayafune, M., Berisio, R., Marchetti, R., Silipo, A., Kayama, M., Desaki, Y., et al. (2014). Chitin-induced activation of immune signaling by the rice receptor CEBiP relies on a unique sandwich-type dimerization. Proc. Natl. Acad. Sci. U. S. A. 111, E404-E413. doi: 10.1073/pnas.1312099111

He, Z. H., Cheeseman, I., He, D., and Kohorn, B. D. (1999). A cluster of five cell wall-associated receptor kinase genes, Wak1-5, are expressed in specific organs of Arabidopsis. Plant Mol. Biol. 39, 1189-1196. doi: 10.1023/A:1006197318246

He, Z. H., Fujiki, M., and Kohorn, B. D. (1996). A cell wall-associated, receptor-like protein kinase. J. Biol. Chem. 271, 19789-19793. doi: 10.1074/jbc.271.33.19789

Henry, G., Deleu, M., Jourdan, E., Thonart, P., and Ongena, M. (2011). The bacterial lipopeptide surfactin targets the lipid fraction of the plant plasma membrane to trigger immune-related defence responses. Cell Microbiol. 13, 1824-1837. doi: 10.1111/j.1462-5822.2011.01664.x

Hurni, S., Scheuermann, D., Krattinger, S. G., Kessel, B., Wicker, T., Herren, G., et al. (2015). The maize disease resistance gene Htnl against northern corn leaf blight encodes a wall-associated receptor-like kinase. Proc. Natl. Acad. Sci. U. S. A. 112, 8780-8785. doi: 10.1073/pnas.1502522112

Jeandroz, S., Wipf, D., Stuehr, D. J., Lamattina, L., Melkonian, M., Tian, Z., et al. (2016). Occurrence, structure, and evolution of nitric oxide synthase-like proteins in the plant kingdom. Sci. Signal 9, re2. doi: 10.1126/scisignal.aad4403

Johnson, J. M., Thürich, J., Petutschnig, E. K., Altschmied, L., Meichsner, D., Sherameti, I., et al. (2018). A Poly(A) ribonuclease controls the cellotriosebased interaction between Piriformospora indica and its host Arabidopsis. Plant Physiol. 176, 2496-2514. doi: 10.1104/pp.17.01423

Joubert, D. A., Kars, I., Wagemakers, L., Bergmann, C., Kemp, G., Vivier, M. A., et al. (2007). A polygalacturonase-inhibiting protein from grapevine reduces the symptoms of the endopolygalacturonase BcPG2 from Botrytis cinerea in Nicotiana benthamiana leaves without any evidence for in vitro interaction. Mol. Plant Microbe Interact. 20, 392-402. doi: 10.1094/ MPMI-20-4-0392

Joubert, D. A., Slaughter, A. R., Kemp, G., Becker, J. V., Krooshof, G. H., Bergmann, C., et al. (2006). The grapevine polygalacturonase-inhibiting protein (VvPGIP1) reduces Botrytis cinerea susceptibility in transgenic tobacco and differentially inhibits fungal polygalacturonases. Transgenic Res. 15, 687702. doi: 10.1007/s11248-006-9019-1

Jourdan, E., Henry, G., Duby, F., Dommes, J., Barthelemy, J., Thonart, P., et al. (2009). insights into the defense-related events occurring in plant cells following perception of surfactin-type lipopeptide from Bacillus subtilis. Mol. Plant-Microbe Interact. 22, 456-468. doi: 10.1094/MPMI-22-4-0456

Kaku, H., Nishizawa, Y., Ishii-Minami, N., Akimoto-Tomiyama, C., Dohmae, N., Takio, K., et al. (2006). Plant cells recognize chitin fragments for defense signaling through a plasma membrane receptor. Proc. Nat. Acad. Sci. U.S.A. 103, 11086-11091. doi: 10.1073/pnas.0508882103

Kalunke, R. M., Tundo, S., Benedetti, M., Cervone, F., De Lorenzo, G., and D’Ovidio, R. (2015). An update on polygalacturonase-inhibiting protein (PGIP), a leucine-rich repeat protein that protects crop plants against pathogens. Front. Plant Sci. 6, 146. doi: 10.3389/fpls.2015.00146

Kars, I., Krooshof, G. H., Wagemakers, L., Joosten, R., Benen, J. A., and van Kan, J. A. (2005). Necrotizing activity of five Botrytis cinerea endopolygalacturonases produced in Pichia pastoris. Plant J. 43, 213-225. doi: 10.1111/j.1365-313X.2005.02436.x
Khalil, M. S., and Badawy, M. E. (2012). Nematicidal activity of a biopolymer chitosan at different molecular weights against root-knot nematode, Meloidogyne incognita. Plant Prot. Sci. 48, 170-178. doi: 10.17221/46/2011-PPS

Klarzynski, O., Plesse, B., Joubert, J. M., Yvin, J. C., Kopp, M., Kloareg, B., et al. (2000). Linear beta-1,3 glucans are elicitors of defense responses in tobacco. Plant Physiol. 124, 1027-1037. doi: 10.1104/pp.124.3.1027

Kunz, C., Vandelle, E., Rolland, S., Poinssot, B., Bruel, C., Cimerman, A., et al. (2006). Characterization of a new, nonpathogenic mutant of Botrytis cinerea with impaired plant colonization capacity. New Phytol. 170, 537-550. doi: 10.1111/j.1469-8137.2006.01682.x

Kutschera, A., Dawid, C., Gisch, N., Schmid, C., Raasch, L., Gerster, T., et al. (2019). Bacterial medium-chain 3-hydroxy fatty acid metabolites trigger immunity in Arabidopsis plants. Science 364, 178-181. doi: 10.1126/science.aau1279

Kutschera, A., and Ranf, S. (2019). The multifaceted functions of lipopolysaccharide in plant-bacteria interactions. Biochimie 159, 93-98. doi: 10.1016/j.biochi. 2018.07.028

Lamotte, O., Gould, K., Lecourieux, D., Sequeira-Legrand, A., Lebrun-Garcia, A., Durner, J., et al. (2004). Analysis of nitric oxide signaling functions in tobacco cells challenged by the elicitor cryptogein. Plant Physiol. 135, 516-529. doi: 10.1104/pp.104.038968

Lecourieux, D., Mazars, C., Pauly, N., Ranjeva, R., and Pugin, A. (2002). Analysis and effects of cytosolic free calcium increases in response to elicitors in Nicotiana plumbaginifolia cells. Plant Cell 14, 2627-2641. doi: 10.1105/ tpc. 005579

Lemaître-Guillier, C., Hovasse, A., Schaeffer-Reiss, C., Recorbet, G., Poinssot, B., Trouvelot, S., et al. (2017). Proteomics towards the understanding of elicitor induced resistance of grapevine against downy mildew. J. Proteomics 156, 113125. doi: 10.1016/j.jprot.2017.01.016

Lenarčič, T., Albert, I., Böhm, H., Hodnik, V., Pirc, K., Zavec, A. B., et al. (2017). Eudicot plant-specific sphingolipids determine host selectivity of microbial NLP cytolysins. Science 358, 1431-1434. doi: 10.1126/science.aan6874

Lerouge, I., and Vanderleyden, J. (2002). O-antigen structural variation: mechanisms and possible roles in animal/plant-microbe interactions. FEMS Microbiol. Rev. 26, 17-47. doi: 10.1111/j.1574-6976.2002.tb00597.x

Li, C. H., Wang, K. C., Hong, Y. H., Chu, T. H., Chu, Y. J., Chou, I. C., et al. (2014). Roles of different forms of lipopolysaccharides in Ralstonia solanacearum pathogenesis. Mol. Plant Microbe Interact. 27, 471-478. doi: 10.1094/MPMI-08-13-0248-R

Li, H., Zhou, S. Y., Zhao, W. S., Su, S. C., and Peng, Y. L. (2009). A novel wallassociated receptor-like protein kinase gene, OsWAK1, plays important roles in rice blast disease resistance. Plant Mol. Biol. 69, 337-346. doi: 10.1007/ s11103-008-9430-5

Li, Y., Héloir, M. C., Zhang, X., Geissler, M., Trouvelot, S., Jacquens, L., et al. (2019). Surfactin and fengycin contribute to the protection of a Bacillus subtilis strain against grape downy mildew by both direct effect and defense stimulation. Mol. Plant Pathol. 20(8), 1037-1050 doi: 10.1111/mpp.12809

Lo Piccolo, S., Ferraro, V., Alfonzo, A., Settanni, L., Ercolini, D., Burruano, S., et al. (2010). Presence of endophytic bacteria in Vitis vinifera leaves as detected by fluorescence in situ hybridization. Ann. Microbiol. 60, 161-167. doi: 10.1007/ s13213-010-0023-6

Locci, F., Benedetti, M., Pontiggia, D., Citterico, M., Caprari, C., Mattei, B., et al. (2019). An Arabidopsis berberine bridge enzyme-like protein specifically oxidizes cellulose oligomers and plays a role in immunity. Plant J. 98, 540-554. doi: $10.1111 /$ tpj.14237

Luna, E., Pastor, V., Robert, J., Flors, V., Mauch-Mani, B., and Ton, J. (2011). Callose deposition: a multifaceted plant defense response. Mol. Plant Microbe Interact. 24, 183-193. doi: 10.1094/MPMI-07-10-0149

Luzuriaga-Loaiza, W. P., Schellenberger, R., De Gaetano, Y., Obounou Akong, F., Villaume, S., Crouzet, J., et al. (2018). Synthetic rhamnolipid bolaforms trigger an innate immune response in Arabidopsis thaliana. Sci. Rep. 8, 8534. doi: 10.1038/s41598-018-26838-y

Maget-Dana, R., and Ptak, M. (1990). Iturin lipopeptides: interactions of mycosubtilin with lipids in planar membranes and mixed monolayers. Biochim. Biophys. Acta 1023, 34-40. doi: 10.1016/0005-2736(90)90006-A

Melotto, M., Underwood, W., Koczan, J., Nomura, K., and He, S. Y. (2006) Plant stomata function in innate immunity against bacterial invasion. Cell 126, 969-980. doi: 10.1016/j.cell.2006.06.054

Miya, A., Albert, P., Shinya, T., Desaki, Y., Ichimura, K., Shirasu, K., et al. (2007). CERK1, a LysM receptor kinase, is essential for chitin elicitor signaling in 
Arabidopsis. Proc. Nat. Acad. Sci. U.S.A. 104, 19613-19618. doi: 10.1073/ pnas.0705147104

Moerschbacher, B. M., Mierau, M., Graeßner, B., Noll, U., and Mort, A. J. (1999). Small oligomers of galacturonic acid are endogenous suppressors of disease resistance reactions in wheat leaves. J. Exp. Bot. 50, 605-612. doi: 10.1093/ jxb/50.334.605

Monnier, N., Furlan, A., Botcazon, C., Dahi, A., Mongelard, G., Cordelier, S., et al. (2018). Rhamnolipids From Pseudomonas aeruginosa are elicitors triggering Brassica napus protection against Botrytis cinerea without physiological disorders. Front. Plant Sci. 9, 1170. doi: 10.3389/fpls.2018.01170

Monnier, N., Furlan, A. L., Buchoux, S., Deleu, M., Dauchez, M., Rippa, S., et al. (2019). Exploring the dual interaction of natural rhamnolipids with plant and fungal biomimetic plasma membranes through biophysical studies. Int. J. Mol. Sci. 20(5), 1009. doi: 10.3390/ijms20051009

Moscatiello, R., Mariani, P., Sanders, D., and Maathuis, F. J. M. (2006). Transcriptional analysis of calcium-dependent and calcium-independent signalling pathways induced by oligogalacturonides. J. Exp. Bot. 57, 2847-2865. doi: $10.1093 / \mathrm{jxb} / \mathrm{erl} 043$

Mueller, K., Bittel, P., Chinchilla, D., Jehle, A., Albert, M., Boller, T., et al. (2012). Chimeric FLS2 receptors reveal the basis for differential flagellin perception in Arabidopsis and tomato. Plant Cell 24, 2213-2224. doi: 10.1105/tpc.112.096073

Mélida, H., Sopeña-Torres, S., Bacete, L., Garrido-Arandia, M., Jordá, L., López, G., et al. (2018). Non-branched $\beta$-1,3-glucan oligosaccharides trigger immune responses in Arabidopsis. Plant J. 93, 34-49. doi: 10.1111/tpj.13755

Ménard, R., Alban, S., de Ruffray, P., Jamois, F., Franz, G., Fritig, B., et al. (2004). Beta-1,3 glucan sulfate, but not beta-1,3 glucan, induces the salicylic acid signaling pathway in tobacco and Arabidopsis. Plant Cell 16, 3020-3032. doi: $10.1105 /$ tpc. 104.024968

Ménard, R., de Ruffray, P., Fritig, B., Yvin, J. C., and Kauffmann, S. (2005). Defense and resistance-inducing activities in tobacco of the sulfated beta-1,3 glucan PS3 and its synergistic activities with the unsulfated molecule. Plant Cell Physiol. 46, 1964-1972. doi: 10.1093/pcp/pci212

Nanni, I. M., Pirondi, A., Contaldo, N., and Collina, M. (2016). Screening of sensitivity to mandipropamid of Plasmopara viticola populations from Italian vineyards by molecular and biological methods. Lett. Appl. Microbiol. 63, 268-273. doi: 10.1111/lam. 12613

Nasir, M. N., Lins, L., Crowet, J. M., Ongena, M., Dorey, S., Dhondt-Cordelier, S., et al. (2017). Differential interaction of synthetic glycolipids with biomimetic plasma membrane lipids correlates with the plant biological response. Langmuir 33, 9979-9987. doi: 10.1021/acs.langmuir.7b01264

Norman, C., Vidal, S., and Palva, E. T. (1999). Oligogalacturonide-mediated induction of a gene involved in jasmonic acid synthesis in response to the cellwall-degrading enzymes of the plant pathogen Erwinia carotovora. Mol. Plant Microbe Interact. 12, 640-644. doi: 10.1094/MPMI.1999.12.7.640

Nunes da Silva, M., Cardoso, A. R., Ferreira, D., Brito, M., Pintado, M. E., and Vasconcelos, M. W. (2014). Chitosan as a biocontrol agent against the pinewood nematode (Bursaphelenchus xylophilus). For. Pathol. 44, 420-423. doi: $10.1111 /$ efp. 12136

Ongena, M., and Jacques, P. (2008). Bacillus lipopeptides: versatile weapons for plant disease biocontrol. Trends Microbiol. 16, 115-125. doi: 10.1016/j.tim.2007.12.009

Paris, F., Krzyżaniak, Y., Gauvrit, C., Jamois, F., Domergue, F., Joubès, J., et al. (2016). An ethoxylated surfactant enhances the penetration of the sulfated laminarin through leaf cuticle and stomata, leading to increased induced resistance against grapevine downy mildew. Physiol. Plant 156, 338-350. doi: 10.1111/ppl.12394

Park, R. D., Jo, K. J., Jo, Y. Y., Jin, Y. L., Kim, K. Y., Shim, J. H., et al. (2002). Variation of antifungal activities of chitosans on plant pathogens. J. Microbiol. Biotechnol. $12,84-88$.

Pauly, M., and Keegstra, K. (2016). Biosynthesis of the plant cell wall matrix polysaccharide xyloglucan. Annu. Rev. Plant Biol. 67, 235-259. doi: 10.1146/ annurev-arplant-043015-112222

Petrocelli, S., Tondo, M. L., Daurelio, L. D., and Orellano, E. G. (2012). Modifications of Xanthomonas axonopodis pv. citri lipopolysaccharide affect the basal response and the virulence process during citrus canker. PLoS One 7, e40051. doi: 10.1371/journal.pone.0040051

Petutschnig, E., Jones, A., Serazetdinova, L., Lipka, U., and Lipka, V. (2010). The Lysin Motif Receptor-like Kinase (LysM-RLK) CERK1 is a major chitin-binding protein in Arabidopsis thaliana and subject to chitin-induced phosphorylation. J. Biol. Chem. 285, 28902-28911. doi: 10.1074/jbc.M110.116657
Poinssot, B. (2002). Caractérisation des réactions de défense de la vigne et identification déliciteurs: léndopolygalacturonase 1 de Botrytis cinerea, une fonction d'avirulence pour un facteur de virulence. PhD Thesis. Dijon (F): Univ. Bourgogne.

Poinssot, B., Vandelle, E., Bentéjac, M., Adrian, M., Levis, C., Brygoo, Y., et al. (2003). The endopolygalacturonase 1 from Botrytis cinerea activates grapevine defense reactions unrelated to its enzymatic activity. Mol. Plant Microbe Interact. 16, 553-564. doi: 10.1094/MPMI.2003.16.6.553

Poupin, M. J., Timmermann, T., Vega, A., Zuñiga, A., and González, B. (2013). Effects of the plant growth-promoting bacterium Burkholderia phytofirmans PsJN throughout the life cycle of Arabidopsis thaliana. PLoS One 8, e69435. doi: 10.1371/journal.pone.0069435

Rabea, E. I., Badawy, M. E., Stevens, C. V., Smagghe, G., and Steurbaut, W. (2003). Chitosan as antimicrobial agent: applications and mode of action. Biomacromolecules 4, 1457-1465. doi: 10.1021/bm034130m

Ranf, S., Gisch, N., Schäffer, M., Illig, T., Westphal, L., Knirel, Y. A., et al. (2015). A lectin S-domain receptor kinase mediates lipopolysaccharide sensing in Arabidopsis thaliana. Nat. Immunol. 16, 426-433. doi: 10.1038/ni.3124

Ranf, S., Scheel, D., and Lee, J. (2016). Challenges in the identification of microbeassociated molecular patterns in plant and animal innate immunity: a case study with bacterial lipopolysaccharide. Mol. Plant Pathol. 17, 1165-1169. doi: 10.1111/mpp. 12452

Rapicavoli, J. N., Blanco-Ulate, B., Muszyński, A., Figueroa-Balderas, R., MoralesCruz, A., Azadi, P., et al. (2018). Lipopolysaccharide O-antigen delays plant innate immune recognition of Xylella fastidiosa. Nat. Commun. 9, 390. doi: 10.1038/s41467-018-02861-5

Rasul, S., Dubreuil-Maurizi, C., Lamotte, O., Koen, E., Poinssot, B., Alcaraz, G., et al. (2012). Nitric oxide production mediates oligogalacturonide-triggered immunity and resistance to Botrytis cinerea in Arabidopsis thaliana. Plant Cell Environ. 35, 1483-1499. doi: 10.1111/j.1365-3040.2012.02505.x

Ren, H., Endo, H., and Hayashi, T. (2001). The superiority of organically cultivated vegetables to general ones regarding antimutagenic activities. Mutat. Res. 496, 83-88. doi: 10.1016/S1383-5718(01)00229-7

Robatzek, S., Bittel, P., Chinchilla, D., Kochner, P., Felix, G., Shiu, S. H., et al. (2007). Molecular identification and characterization of the tomato flagellin receptor LeFLS2, an orthologue of Arabidopsis FLS2 exhibiting characteristically different perception specificities. Plant Mol. Biol. 64, 539-547. doi: 10.1007/s11103-007-9173-8

Rosli, H. G., Zheng, Y., Pombo, M. A., Zhong, S., Bombarely, A., Fei, Z., et al. (2013). Transcriptomics-based screen for genes induced by flagellin and repressed by pathogen effectors identifies a cell wall-associated kinase involved in plant immunity. Genome Biol. 14, R139. doi: 10.1186/gb-2013-14-12-r139

Rotblat, B., Enshell-Seijffers, D., Gershoni, J. M., Schuster, S., and Avni, A. (2002). Identification of an essential component of the elicitation active site of the EIX protein elicitor. Plant J. 32, 1049-1055. doi: 10.1046/j.1365-313X.2002.01490.x Saintenac, C., Lee, W. S., Cambon, F., Rudd, J. J., King, R. C., Marande, W., et al. (2018). Wheat receptor-kinase-like protein Stb6 controls gene-for-gene resistance to fungal pathogen Zymoseptoria tritici. Nat. Genet. 50, 368-374. doi: 10.1038/s41588-018-0051-x

Sanchez, L., Courteaux, B., Hubert, J., Kauffmann, S., Renault, J. H., Clément, C., et al. (2012). Rhamnolipids elicit defense responses and induce disease resistance against biotrophic, hemibiotrophic, and necrotrophic pathogens that require different signaling pathways in Arabidopsis and highlight a central role for salicylic acid. Plant Physiol. 160, 1630-1641. doi: 10.1104/pp.112.201913

Shang-Guan, K., Wang, M., Htwe, N. M. P. S., Li, P., Li, Y., Qi, F., et al. (2018). Lipopolysaccharides trigger two successive bursts of reactive oxygen species at distinct cellular locations. Plant Physiol. 176, 2543-2556. doi: 10.1104/ pp.17.01637

Shimizu, T., Nakano, T., Takamizawa, D., Desaki, Y., Ishii-Minami, N., Nishizawa, Y., et al. (2010). Two LysM receptor molecules, CEBiP and OsCERK1, cooperatively regulate chitin elicitor signaling in rice. Plant J. 64, 204-214. doi: 10.1111/j. 1365-313X.2010.04324.x

Silipo, A., Molinaro, A., Sturiale, L., Dow, J. M., Erbs, G., Lanzetta, R., et al. (2005). The elicitation of plant innate immunity by lipooligosaccharide of Xanthomonas campestris. J. Biol. Chem. 280, 33660-33668. doi: 10.1074/ jbc.M506254200

Simpson, S. D., Ashford, D. A., Harvey, D. J., and Bowles, D. J. (1998). Short chain oligogalacturonides induce ethylene production and expression of the gene encoding aminocyclopropane 1-carboxylic acid oxidase in tomato plants. Glycobiology 8, 579-583. doi: 10.1093/glycob/8.6.579 
Sivaguru, M., Ezaki, B., He, Z. H., Tong, H., Osawa, H., Baluska, F., et al. (2003). Aluminum-induced gene expression and protein localization of a cell wallassociated receptor kinase in Arabidopsis. Plant Physiol. 132, 2256-2266. doi: 10.1104/pp.103.022129

Souza, C. A., Li, S., Lin, A. Z., Boutrot, F., Grossmann, G., Zipfel, C., et al. (2017). Cellulose-derived oligomers act as damage-associated molecular patterns and trigger defense-like responses. Plant Physiol. 173, 2383-2398. doi: 10.1104/ pp. 16.01680

Sun, F., Zhang, P., Guo, M., Yu, W., and Chen, K. (2013). Burdock fructooligosaccharide induces fungal resistance in postharvest Kyoho grapes by activating the salicylic acid-dependent pathway and inhibiting browning. Food Chem. 138, 539-546. doi: 10.1016/j.foodchem.2012.10.058

Sun, W., Dunning, F., Pfund, C., Weingarten, R., and Bent, A. (2006). Withinspecies flagellin polymorphism in Xanthomonas campestris $p v$ campestris and its impact on elicitation of Arabidopsis FLAGELLIN SENSING2-dependent defenses. Plant Cell 18, 764-779. doi: 10.1105/tpc.105.037648

Takai, R., Isogai, A., Takayama, S., and Che, F. (2008). Analysis of flagellin perception mediated by flg22 receptor OsFLS2 in rice. Mol. Plant-Microbe Interact. 21, 1635-1642. doi: 10.1094/MPMI-21-12-1635

Takeda, T., Furuta, Y., Awano, T., Mizuno, K., Mitsuishi, Y., and Hayashi, T. (2002). Suppression and acceleration of cell elongation by integration of xyloglucans in pea stem segments. Proc. Natl. Acad. Sci. U. S. A. 99, 9055-9060. doi: 10.1073/ pnas. 132080299

ten Have, A., Breuil, W. O., Wubben, J. P., Visser, J., and van Kan, J. A. (2001). Botrytis cinerea endopolygalacturonase genes are differentially expressed in various plant tissues. Fungal Genet. Biol. 33, 97-105. doi: 10.1006/fgbi.2001.1269

ten Have, A., Mulder, W., Visser, J., and van Kan, J. A. (1998). The endopolygalacturonase gene $B c p g 1$ is required for full virulence of Botrytis cinerea. Mol. Plant Microbe Interact. 11, 1009-1016. doi: 10.1094/ MPMI.1998.11.10.1009

ten Have, A., Tenberge, K. B., Benen, J. A. E., Tudzynski, P., Visser, J., and van Kan, J. A. L., (2002). "The contribution of cell wall degrading enzymes to pathogenesis of fungal plant pathogens," in Agricultural Applications. Springer Berlin Heidelberg. Ed. F. Kempken (Berlin, Heidelberg: Springer), 341-358. doi: 10.1007/978-3-662-03059-2_17

Theocharis, A., Bordiec, S., Fernandez, O., Paquis, S., Dhondt-Cordelier, S., Baillieul, F., et al. (2012). Burkholderia phytofirmans PsJN primes Vitis vinifera L. and confers a better tolerance to low nonfreezing temperatures. Mol. PlantMicrobe Interact. 25, 241-249. doi: 10.1094/MPMI-05-11-0124

Tikhonov, V. E., Stepnova, E. A., Babak, V. G., Yamskov, I. A., Palma-Guerrero, J., Jansson, H.-B., et al. (2006). Bactericidal and antifungal activities of a low molecular weight chitosan and its $\mathrm{N}-/ 2$ (3)-(dodec-2-enyl)succinoyl/derivatives. Carbohydr. Polym. 64, 66-72. doi: 10.1016/j.carbpol.2005.10.021

Trdá, L. (2014). Identification et caractérisation du récepteur à la flagelline (VvFLS2) et recherche du récepteur aux chito-oligosaccharides chez la vigne. Dijon (F): PhD Thesis. Univ. Bourgogne.

Trdá, L., Boutrot, F., Claverie, J., Brulé, D., Dorey, S., and Poinssot, B. (2015). Perception of pathogenic or beneficial bacteria and their evasion of host immunity: pattern recognition receptors in the frontline. Front. Plant Sci. 6, 219. doi: 10.3389/fpls.2015.00219

Trdá, L., Fernandez, O., Boutrot, F., Héloir, M. C., Kelloniemi, J., Daire, X., et al. (2014). The grapevine flagellin receptor VvFLS2 differentially recognizes flagellin-derived epitopes from the endophytic growth-promoting bacterium Burkholderia phytofirmans and plant pathogenic bacteria. New Phytol. 201, 1371-1384. doi: 10.1111/nph.12592

Trotel-Aziz, P., Couderchet, M., Vernet, G., and Aziz, A. (2006). Chitosan stimulates defense reactions in grapevine leaves and inhibits development of Botrytis cinerea. Eur. J. Plant Pathol. 114, 405-413. doi: 10.1007/s10658-006-0005-5

Trouvelot, S., Héloir, M. C., Poinssot, B., Gauthier, A., Paris, F., Guillier, C., et al. (2014). Carbohydrates in plant immunity and plant protection: roles and potential application as foliar sprays. Front. Plant Sci. 5, 592. doi: 10.3389/ fpls.2014.00592

Trouvelot, S., Varnier, A. L., Allègre, M., Mercier, L., Baillieul, F., Arnould, C., et al. (2008). A beta-1,3 glucan sulfate induces resistance in grapevine against Plasmopara viticola through priming of defense responses, including HR-like cell death. Mol. Plant Microbe Interact. 21, 232-243. doi: 10.1094/ MPMI-21-2-0232 van Aubel, G., Buonatesta, R., and Van Cutsem, P. (2014). COS-OGA: a novel oligosaccharidic elicitor that protects grapes and cucumbers against powdery mildew. Crop Prot. 65, 129-137. doi: 10.1016/j.cropro.2014.07.015

van der Hoorn, R. A., and Kamoun, S. (2008). From guard to decoy: a new model for perception of plant pathogen effectors. Plant Cell 20, 2009-2017. doi: 10.1105/tpc.108.060194

Vandelle, E., Poinssot, B., Wendehenne, D., Bentejac, M., and Pugin, A. (2006). Integrated signaling network involving calcium, nitric oxide, and active oxygen species but not mitogen-activated protein kin in BcPG1-elicited grapevine defenses. Mol. Plant-Microbe Interact. 19, 429-440. doi: 10.1094/ MPMI-19-0429

Vargas-Rechia, C., Reicher, F., Rita Sierakowski, M., Heyraud, A., Driguez, H., and Linart, Y. (1998). Xyloglucan octasaccharide XXLGol derived from the seeds of Hymenaea courbaril acts as a signaling molecule. Plant Physiol. 116, 10131021. doi: 10.1104/pp.116.3.1013

Varnier, A. L., Sanchez, L., Vatsa, P., Boudesocque, L., Garcia-Brugger, A., Rabenoelina, F., et al. (2009). Bacterial rhamnolipids are novel MAMPs conferring resistance to Botrytis cinerea in grapevine. Plant Cell Environ. 32, 178-193. doi: 10.1111/j.1365-3040.2008.01911.x

Vasiukova, N. I., Zinov'eva, S. V., Il'inskaia, L. I., Perekhod, E. A., Chalenko, G. I., Gerasimova, N. G., et al. (2001). Modulation of plant resistance to diseases by water-soluble chitosan. Prikl. Biokhim. Mikrobiol. 37, 115-122.

Vatsa, P., Sanchez, L., Clement, C., Baillieul, F., and Dorey, S. (2010). Rhamnolipid biosurfactants as new players in animal and plant defense against microbes. Int. J. Mol. Sci. 11, 5095-5108. doi: 10.3390/ijms11125095

Vetter, M., Kronholm, I., He, F., Haweker, H., Reymond, M., Bergelson, J., et al. (2012). Flagellin perception varies quantitatively in Arabidopsis thaliana and its relatives. Mol. Biol. Evol. 29, 1655-1667. doi: 10.1093/molbev/mss011

Wagner, T. A., and Kohorn, B. D. (2001). Wall-associated kinases are expressed throughout plant development and are required for cell expansion. Plant Cell 13, 303-318. doi: 10.1105/tpc.13.2.303

Walters, D. R., and Fountaine, J. M. (2009). Practical application of induced resistance to plant diseases: an appraisal of effectiveness under field conditions. J. Agric. Sci. 147, 523-535. doi: 10.1017/S0021859609008806

Walters, D. R., Ratsep, J., and Havis, N. D. (2013). Controlling crop diseases using induced resistance: challenges for the future. J. Exp. Bot. 64, 1263-1280. doi: 10.1093/jxb/ert026

Wan, J., Zhang, X., Neece, D., Ramonell, K., Clough, S., Kim, S., et al. (2008). A LysM receptor-like kinase plays a critical role in chitin signaling and fungal resistance in Arabidopsis. Plant Cell 20, 471-481. doi: 10.1105/tpc.107.056754

Wang, X., Tu, M., Wang, D., Liu, J., Li, Y., Li, Z., et al. (2018). CRISPR/Cas9mediated efficient targeted mutagenesis in grape in the first generation. Plant Biotechnol. J. 16, 844-855. doi: 10.1111/pbi.12832

Wendehenne, D., Lamotte, O., Frachisse, J., Barbier-Brygoo, H., and Pugin, A. (2002). Nitrate efflux is an essential component of the cryptogein signaling pathway leading to defense responses and hypersensitive cell death in tobacco. Plant Cell 14, 1937-1951. doi: 10.1105/tpc.002295

Whitney, S. E., Wilson, E., Webster, J., Bacic, A., Reid, J. S., and Gidley, M. J. (2006). Effects of structural variation in xyloglucan polymers on interactions with bacterial cellulose. Am. J. Bot. 93, 1402-1414. doi: 10.3732/ajb.93.10.1402

Wiesel, L., Newton, A. C., Elliott, I., Booty, D., Gilroy, E. M., Birch, P. R., et al. (2014). Molecular effects of resistance elicitors from biological origin and their potential for crop protection. Front. Plant Sci. 5, 655. doi: 10.3389/ fpls.2014.00655

Yang, P., Praz, C., Li, B., Singla, J., Robert, C. A. M., Kessel, B., et al. (2019). Fungal resistance mediated by maize wall-associated kinase ZmWAK-RLK1 correlates with reduced benzoxazinoid content. New Phytol. 221, 976-987. doi: 10.1111/ nph.15419

Zeng, W., and He, S. Y. (2010). A prominent role of the flagellin receptor FLAGELLIN-SENSING2 in mediating stomatal response to Pseudomonas syringae pv tomato DC3000 in Arabidopsis. Plant Physiol. 153, 1188-1198. doi: $10.1104 / \mathrm{pp} .110 .157016$

Zhang, L., Kars, I., Essenstam, B., Liebrand, T. W., Wagemakers, L., Elberse, J., et al. (2014). Fungal endopolygalacturonases are recognized as microbe-associated molecular patterns by the Arabidopsis receptor-like protein responsiveness to Botrytis polygalacturonases1. Plant Physiol. 164, 352-364. doi: 10.1104/ pp.113.230698 
Zhang,L., andvan Kan,J.A.L.(2013). Pectin as a barrier and nutrient source for fungal plant pathogens. Agric. Appl. pp, 361-375. doi: 10.1007/978-3-642-36821-9_14

Zhang, N., Zhang, B., Zuo, W., Xing, Y., Konlasuk, S., Tan, G., et al. (2017). Cytological and molecular characterization of ZmWAK-mediated head-smut resistance in maize. Mol. Plant Microbe Interact. 30, 455-465. doi: 10.1094/ MPMI-11-16-0238-R

Zhang, S., Chen, C., Li, L., Meng, L., Singh, J., Jiang, N., et al. (2005). Evolutionary expansion, gene structure, and expression of the rice wallassociated kinase gene family. Plant Physiol. 139, 1107-1124. doi: 10.1104/ pp.105.069005

Zhang, X., Zhou, Y., Li, Y., Fu, X., and Wang, Q. (2017). Screening and characterization of endophytic Bacillus for biocontrol of grapevine downy mildew. Crop Prot. 96, 173-179. doi: 10.1016/j.cropro.2017.02.018

Zipfel, C., Robatzek, S., Navarro, L., Oakeley, E. J., Jones, J. D. G., Felix, G., et al. (2004). Bacterial disease resistance in Arabidopsis through flagellin perception. Nature 428, 764-767. doi: 10.1038/nature02485

Zou, Y., Wang, S., Zhou, Y., Bai, J., Huang, G., Liu, X., et al. (2018). Transcriptional regulation of the immune receptor FLS2 controls the ontogeny of plant innate immunity. Plant Cell 30, 2779-2794. doi: 10.1105/ tpc. 18.00297
Zuniga, A., Poupin, M., Donoso, R., Ledger, T., Guiliani, N., Gutierrez, R., et al. (2013). Quorum sensing and indole-3-acetic acid degradation play a role in colonization and plant growth promotion of Arabidopsis thaliana by Burkholderia phytofirmans PsJN. Mol. Plant-Microbe Interact. 26, 546-553. doi: 10.1094/MPMI-10-12-0241-R

Zuo, W., Chao, Q., Zhang, N., Ye, J., Tan, G., Li, B., et al. (2015). A maize wallassociated kinase confers quantitative resistance to head smut. Nat. Genet. 47, 151-157. doi: 10.1038/ng.3170

Conflict of Interest Statement: The authors declare that the research was conducted in the absence of any commercial or financial relationships that could be construed as a potential conflict of interest.

Copyright (C) 2019 Héloir, Adrian, Brulé, Claverie, Cordelier, Daire, Dorey, Gauthier, Lemaître-Guillier, Negrel, Trdá, Trouvelot, Vandelle and Poinssot. This is an openaccess article distributed under the terms of the Creative Commons Attribution License (CC BY). The use, distribution or reproduction in other forums is permitted, provided the original author(s) and the copyright owner(s) are credited and that the original publication in this journal is cited, in accordance with accepted academic practice. No use, distribution or reproduction is permitted which does not comply with these terms. 